\title{
Dorsoventral-Specific Effects of Nerve Agent Surrogate Diisopropylfluorophosphate on Synaptic Transmission in the Mouse Hippocampus\$
}

\author{
Kyle A. Brown, Nikolay M. Filipov, and John J. Wagner \\ Department of Physiology and Pharmacology and Interdisciplinary Toxicology Program, University of Georgia, Athens, GA
}

Received October 3, 2019; accepted December 16, 2019

\begin{abstract}
Although there has been an increasing appreciation for functional differences between the dorsal $(\mathrm{dH})$ and ventral $(\mathrm{vH})$ hippocampal sectors, there is a lack of information characterizing the cholinergic and noncholinergic mechanisms of acetylcholinesterase inhibitors on synaptic transmission along the hippocampal dorsoventral axis. Diisopropylfluorophosphate (DFP) is an organophosphate (OP) that is commonly employed as a nerve agent surrogate in vitro as well as in rodent models of disease states, such as Gulf War Illness. The present study investigated the cholinergic and noncholinergic mechanisms responsible for the effects of acute DFP exposure on $\mathrm{dH}$ and $\mathrm{vH}$ synaptic transmission in a hippocampal slice preparation. A paired-pulse extracellular recording protocol was used to monitor the population spike (PS) amplitude as well as the PS paired-pulse ratio (PS-PPR) in the CA1 subfield of the $\mathrm{dH}$ and the $\mathrm{vH}$. We observed that DFP-induced PS1 inhibition was produced by a cholinergic mechanism in the $\mathrm{dH}$, whereas a noncholinergic mechanism was indispensable in mediating the inhibitory effect of DFP on the PS1 in the vH. PS-PPR in both $\mathrm{dH}$ and $\mathrm{vH}$ sectors
\end{abstract}

was increased by acute DFP exposure, an effect that was blocked by an N-methyl-D-aspartate receptor antagonist but not by cholinergic antagonists. Clinical reports have indicated dorsoventral-specific hippocampal abnormalities in cases of OP intoxications. Therefore, the observed dorsoventral-specific noncholinergic mechanisms underlying the effects of DFP on hippocampal synaptic transmission may have important implications for the treatment of OP overexposures.

\section{SIGNIFICANCE STATEMENT}

It is unknown if acetylcholinesterase inhibitors differentially impact dorsal and ventral hippocampal synaptic transmission. The data in the present study show that an organophosphate, diisopropylfluorophosphate, impacts glutamatergic transmission along the dorsoventral axis in a hippocampal slice preparation via distinct cholinergic and noncholinergic mechanisms. These findings may provide insight into investigations of therapeutic agents that target noncholinergic mechanisms in cases of organophosphate overexposures.

\section{Introduction}

The hippocampus is a bilateral structure located in the medial temporal lobe of mammalian organisms and plays a fundamental role in learning and memory. Over the past decade, there has been increasing appreciation for differential functionality between the posterior [dorsal $(\mathrm{dH})]$ and anterior [ventral (vH)] hippocampal sectors (Bannerman et al., 2004; Fanselow and Dong, 2010). For instance, the $\mathrm{dH}$ is associated with spatial memory, whereas the $\mathrm{vH}$ is linked to emotional and stress-related responses (Bannerman et al., 2004). In

This research was supported by the Department of Defense Congressionally Directed Medical Research Programs [Grant W81XWH-16-1-0586] to N.M.F. K.A.B. received support from the Interdisciplinary Toxicology Program at the University of Georgia.

https://doi.org/10.1124/jpet.119.263053.

S This article has supplemental material available at jpet.aspetjournals.org. both sectors, hippocampal-dependent behavior is regulated by synaptic plasticity and transmission (Whitlock et al., 2006). Hippocampal synaptic transmission is driven by excitatory neurotransmitters like glutamate and shaped by inhibitory neurotransmitters such as $\gamma$-aminobutyric acid (GABA) (Watkins and Evans, 1981). Another neurotransmitter, acetylcholine (ACh), modulates hippocampal pyramidal cell activity (Benardo and Prince, 1982a,b; Madison et al., 1987), consequently influencing hippocampal memory functions (Hasselmo, 2006). For instance, cholinergic projections from the medial septum and diagonal band to the hippocampal formation are involved in controlling hippocampal theta rhythms (Stewart and Fox, 1990; Vertes and Kocsis, 1997; Hasselmo, 2006). Although there is some evidence for differential cholinergic projection (Milner et al., 1983; Amaral and Kurz, 1985) and receptor density (Garcia Ruiz et al., 1993; Jung et al., 1994; Huang and Winzer-Serhan, 2006; Kenney et al., 2012)

ABBREVIATIONS: ACh, acetylcholine; AChE, acetylcholinesterase; AFDX-116(11-[[2-[(Diethylamino)methyl]-1-piperidinyl]acetyl]-5,11-dihydro-6H-pyrido [2,3-b][1,4]benzodiazepin-6-one),ATR, atropine; DAN, dantrolene; DFP, diisopropylfluorophosphate; D-APV, D-(-)-2-Amino-5- phosphonopentanoic acid; $\mathrm{dH}$, dorsal hippocampus; I/O curve, input-output curve; mAChR, metabotropic muscarinic; MEC, mecamylamine; nAChR, ionotropic nicotinic; NMDAR, $\mathrm{N}$-methyl-D-aspartate receptor; OP, organophosphate; PS, population spike; PS-PPF, population spike paired-pulse facilitation; PS-PPI, population spike paired-pulse inhibition; PS-PPR, population spike paired-pulse ratio; PZP, pirenzepine; RI, recurrent inhibition; RyR, ryanodine receptor; vH, ventral hippocampus. 


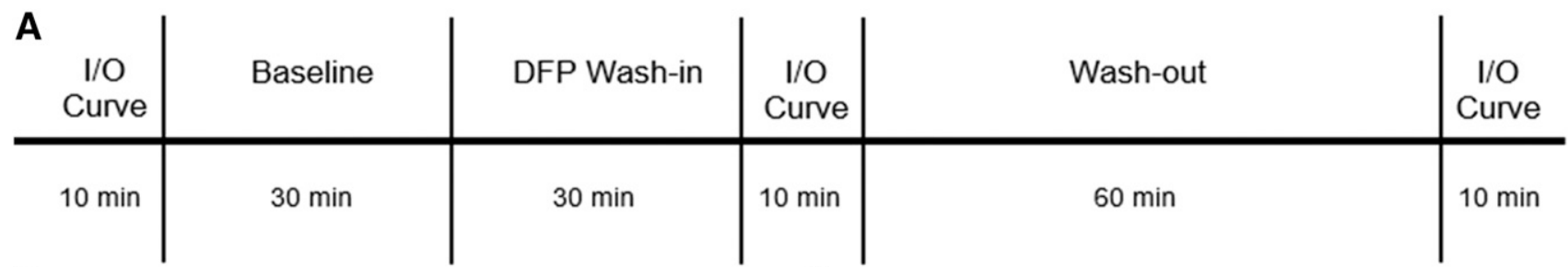

B

DFP PS ${ }_{1}$ Dose-response Curve in the $\mathrm{dH}$

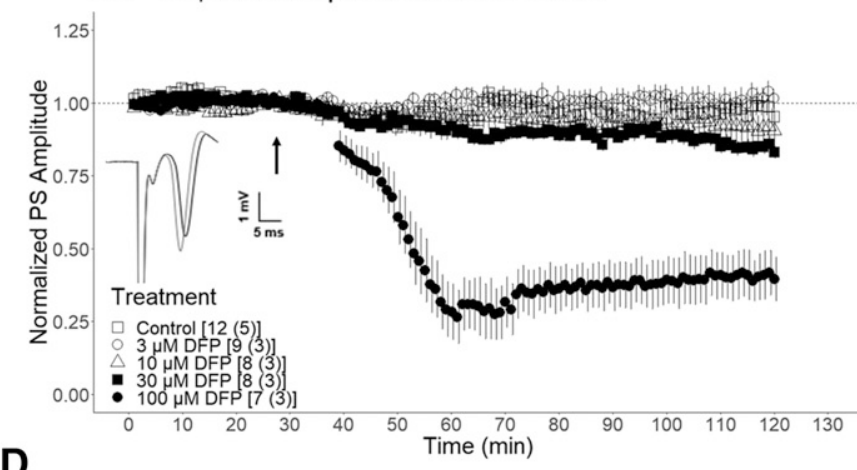

D

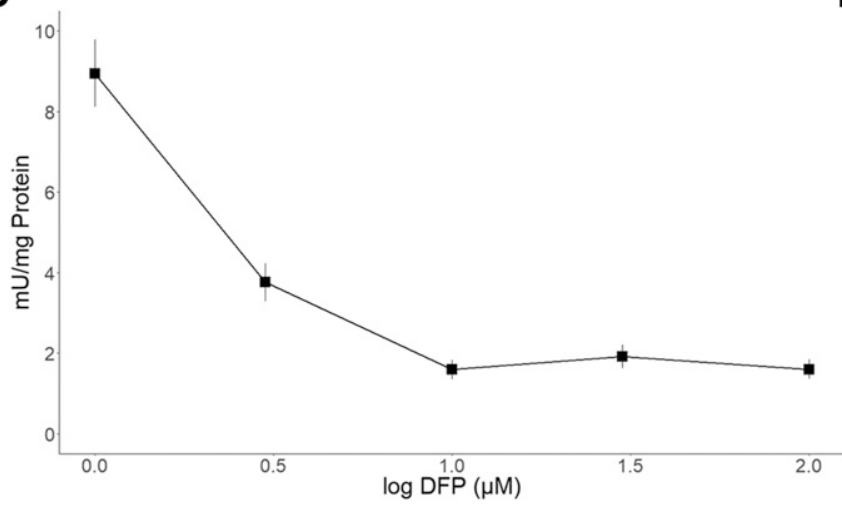

C

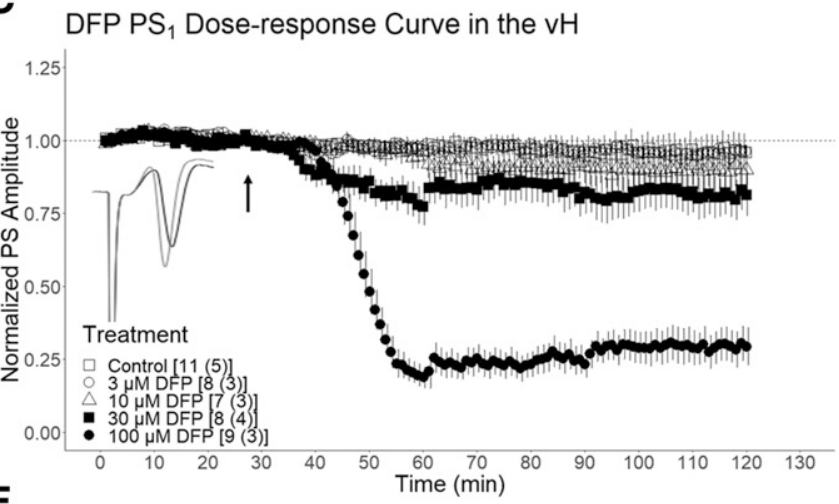

E

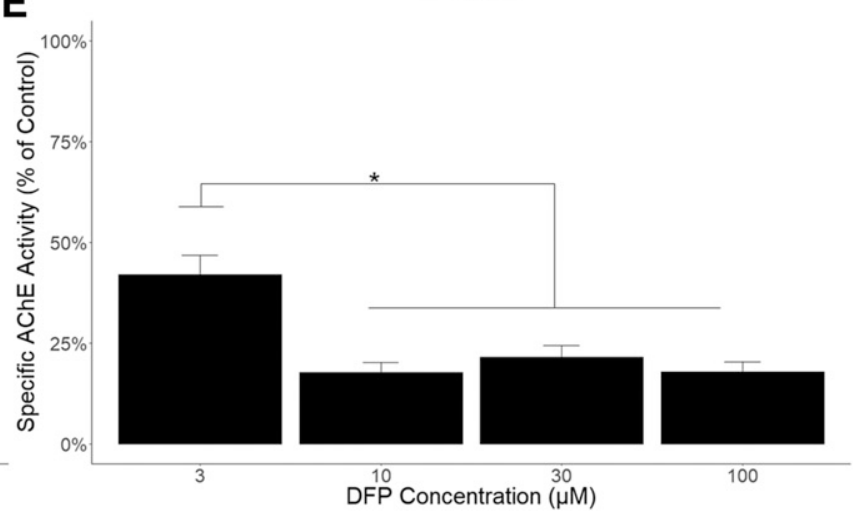

Fig. 1. The effect of diisopropylfluorophosphate (DFP) wash-in on the population spike (PS1) and AChE activity in the dorsal (dH) and the ventral (vH) hippocampus. (A) Timeline of DFP wash-in experiments. (B and C) Results of dose-response curve experiments investigating the effect of DFP on the PS1 in the $\mathrm{dH}(\mathrm{B})$ and the $\mathrm{vH}(\mathrm{C})$. Slices were exposed to DFP as indicated by the arrow at 30 minutes. Reported $n$ values $[x(y)]$ indicate the number of slices $(x)$ and the number of mice $(y)$ assessed. Representative traces of the baseline PS1 (gray) and the PS1 following 60 minutes $30 \mu M$ DFP wash-out (black) are shown. (D and E) Acetylcholinesterase (AChE) activity in $\mathrm{dH}$ and $\mathrm{vH}$ slices exposed to DFP for 30 minutes and washed with ACSF for 80 minutes $\left(\mathrm{IC}_{50}=2.70 \mu \mathrm{M}\right)$. Each data point represents the average AChE activity from 12 slices (collected from the $\mathrm{dH}$ and the vH). $*$ denotes $\mathrm{p}<0.05$. Data are expressed as mean \pm S.E.M. I/O curve, input-output curve.

in the $\mathrm{dH}$ compared with the $\mathrm{vH}$, there is a paucity of reports investigating the distinct role of ACh in synaptic transmission along the hippocampal dorsoventral axis.

Organophosphates (OPs) are potent neurotoxicants that are frequently employed in agricultural and military settings (Naughton and Terry, 2018). OPs phosphorylate the serine hydroxyl group in the catalytic triad of acetylcholinesterase (AChE), irreversibly inhibiting the enzyme (Abou-Donia, 2003). Subsequent enhancement of synaptic ACh levels leads to cholinergic modulation of hippocampal glutamatergic transmission via activation of metabotropic muscarinic ( $\mathrm{mAChR}$ ) and ionotropic nicotinic $(\mathrm{nAChR}) \mathrm{ACh}$ receptors. If not aggressively treated, acute OP-induced cholinergic hyperactivity precipitates the presentation of cholinergic crisis followed by glutamatergic-mediated persistence of seizures and, ultimately, death (Abou-Donia et al., 2016).

Exposure to OPs also induces persisting toxicity via multiple noncholinergic mechanisms, i.e., by affecting oxidant formation, mitochondrial energetics, axoplasmic transport, immune system functionality, and brain endocannabinoid homeostasis (Casida and Quistad, 2004; Pope et al., 2005; Mense et al., 2006; Nallapaneni et al., 2006; Kaur et al., 2007; Grigoryan et al., 2008; Nallapaneni et al., 2008; Grigoryan et al., 2009; Jiang et al., 2010; Middlemore-Risher et al., 2010; Wright et al., 2010; Rohlman et al., 2011; Banks and Lein, 2012; O'Callaghan et al., 2015; Locker et al., 2017; Miller et al., 2018; Naughton et al., 2018; Naughton and Terry, 2018; Michalovicz et al., 2019). Nevertheless, it is unknown if such noncholinergic effects differentially impact synaptic transmission along the hippocampal dorsoventral axis.

Low-level exposure to OPs in a variety of settings has been consistently associated with learning and memory impairments in humans. Repeated subacute OP insecticide exposure in agricultural settings has been linked with impairments in short-term memory (Kaplan et al., 1993; Eaton et al., 2008; Rohlman et al., 2011; Ross et al., 2013). Aerotoxic syndrome, an occupational disease linked to exposure to OPs circulating in unfiltered aircraft cabin air, is associated with cognitive 

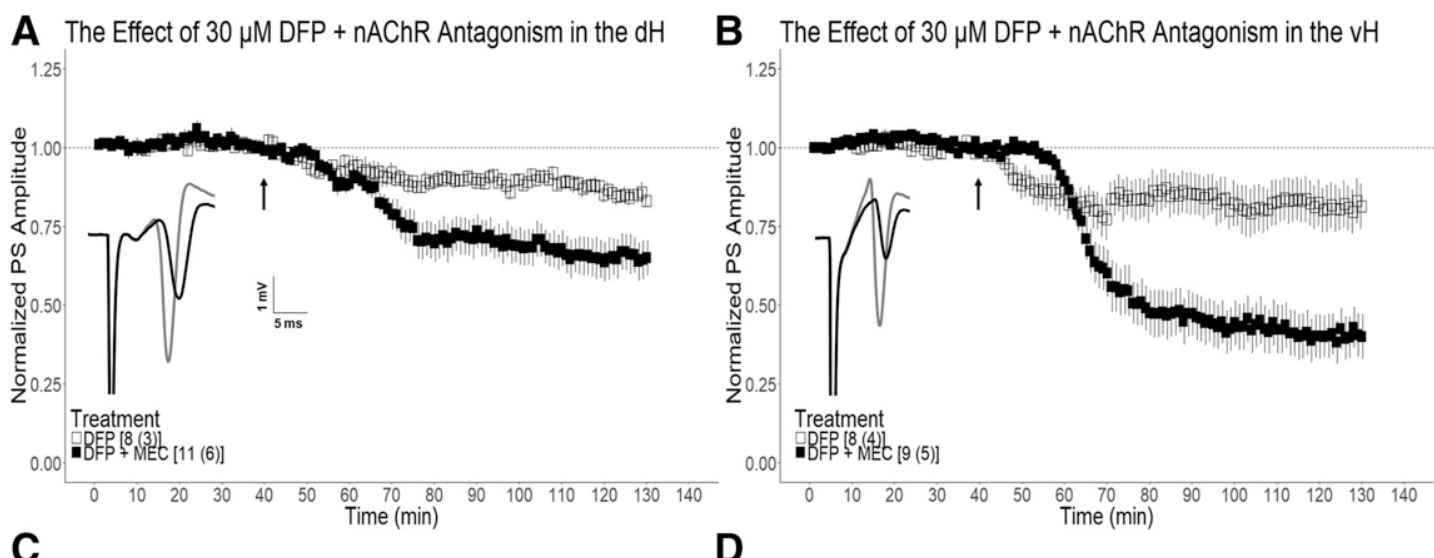

C The Effect of $30 \mu \mathrm{M} D F P+m A C h R$ Antagonism in the $\mathrm{dH}$
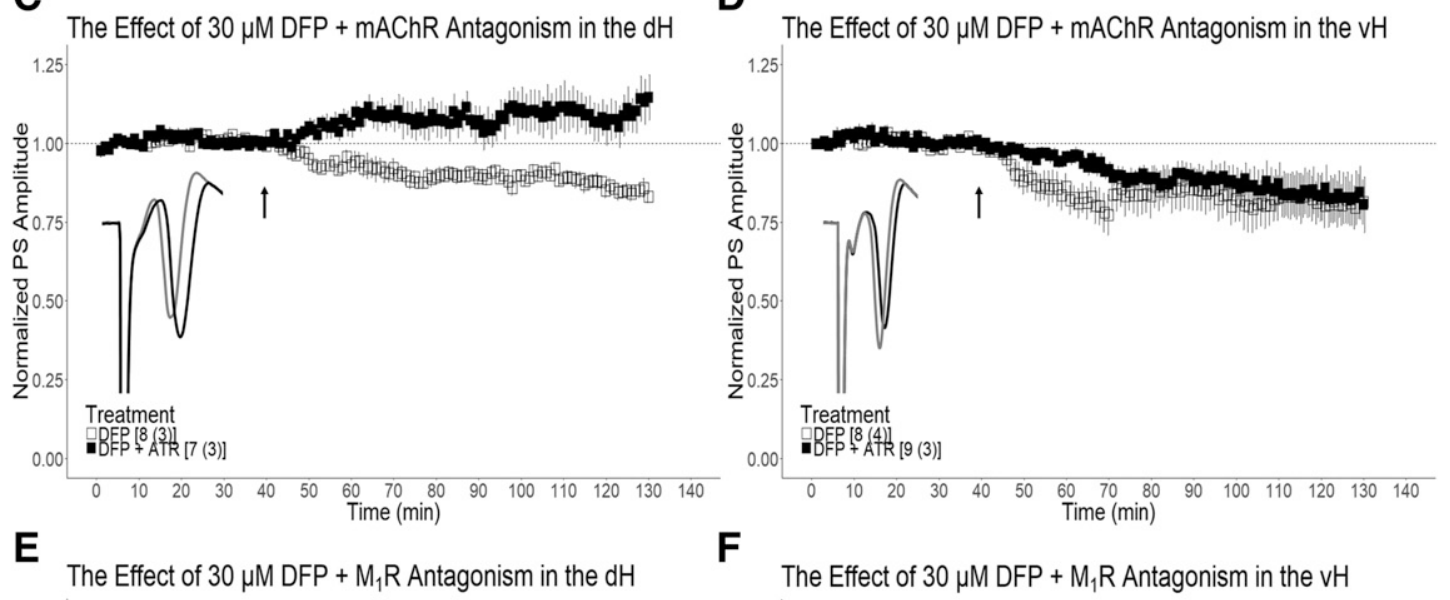

$\mathbf{F}$
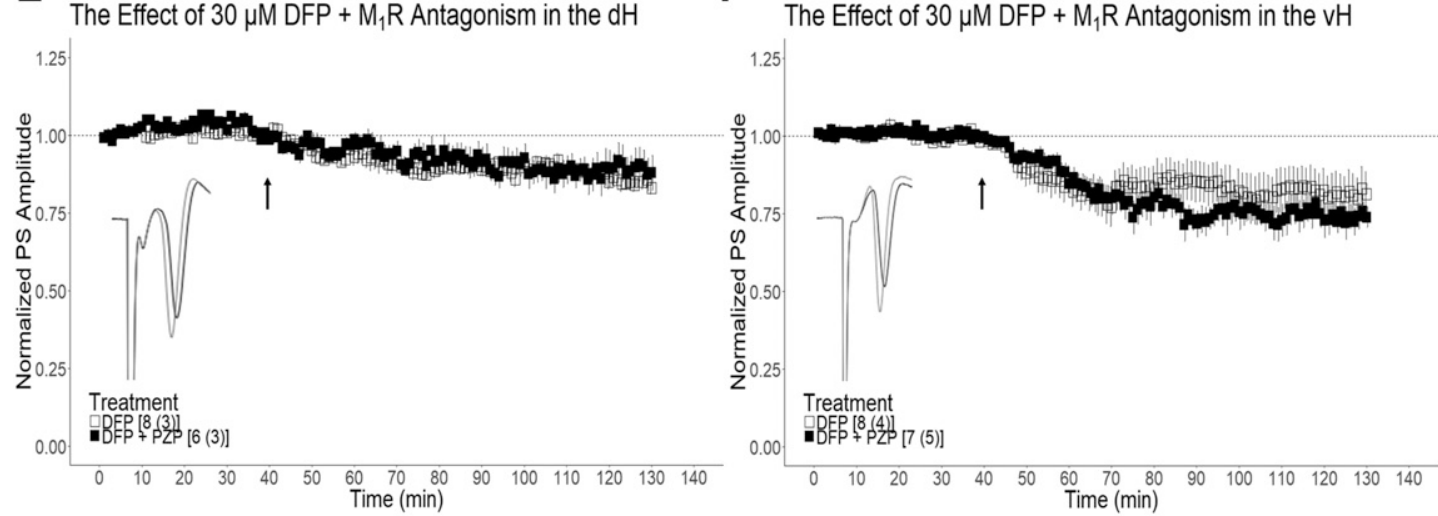

G The Effect of $30 \mu \mathrm{M} D F P+M_{2} R$ Antagonism in the $d H$

H
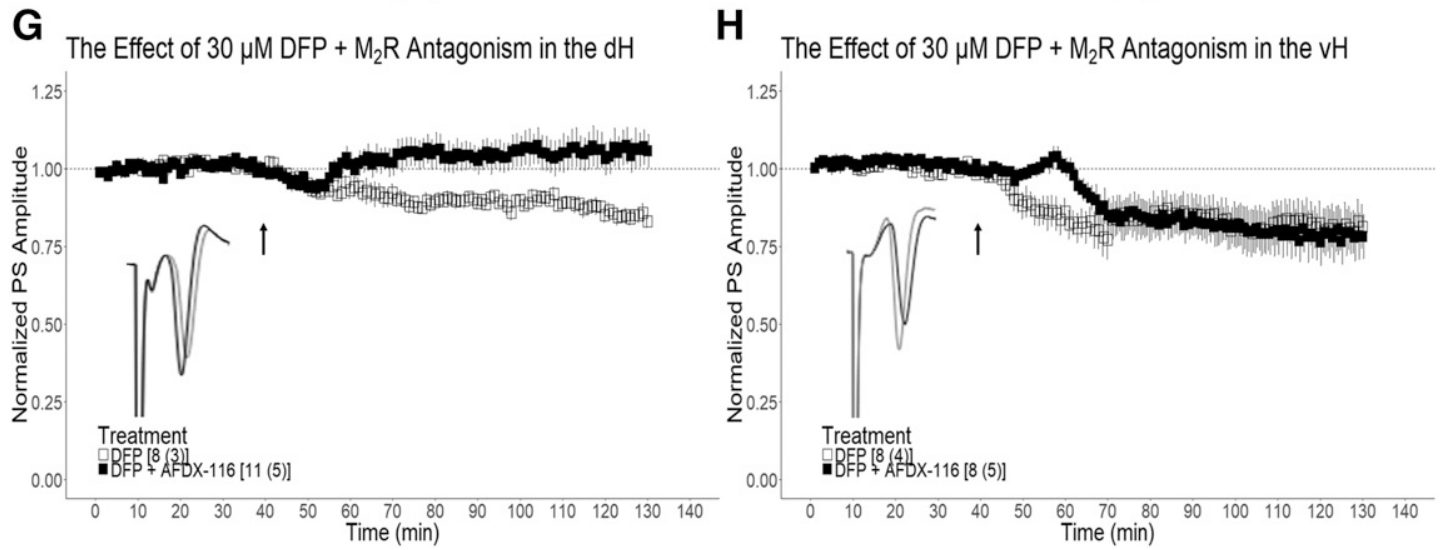

Fig. 2. Cholinergic antagonist pretreatment prevents DFP-mediated PS1 inhibition in the dH but not in the vH. (A and B) The effect of $30 \mu M$ mecamylamine (MEC) pretreatment on $30 \mu \mathrm{M}$ DFP-mediated PS1 inhibition in the $\mathrm{dH}$ (A) and the vH (B). (C and D) The effect of $3 \mu \mathrm{M}$ atropine (ATR) pretreatment on $30 \mu \mathrm{M}$ DFP-mediated PS1 inhibition in the $\mathrm{dH}(\mathrm{C})$ and the $\mathrm{vH}(\mathrm{D})$. (E and F) The effect of $100 \mathrm{nM}$ pirenzepine (PZP) pretreatment on $30 \mu \mathrm{M}$ DFP-mediated PS1 inhibition in the $\mathrm{dH}(\mathrm{E})$ and the $\mathrm{vH}(\mathrm{F})$. (G and H) The effect of $300 \mathrm{nM}$ AFDX-116 pretreatment on $30 \mu \mathrm{M}$ DFP-mediated PS1 inhibition in the $\mathrm{dH}(\mathrm{G})$ and the $\mathrm{vH}(\mathrm{H})$. In antagonist experiments, slices were pretreated with antagonist(s) following 20 minutes of baseline recording. 
deficits (Michaelis et al., 2017). Additionally, civilians exposed to OP nerve agents in the Tokyo metro terror attacks (Hood, 2001; Nishiwaki et al., 2001; Miyaki et al., 2005) and in Kurdistan during the Iran-Iraq war (Talabani et al., 2018) present persisting neurologic impairments, including cognitive deficits. Moreover, US veterans of the 1990 to 1991 Persian Gulf War exhibit dose-dependent associations between OP exposure and impaired performance on neurobehavioral tasks (Proctor et al., 2006) as well as decreased white matter volume (Heaton et al., 2007). Notably, the performance of veterans with Gulf War Illness and predicted sarin exposure in a learning and memory task is negatively correlated with estimated exposure levels (Chao et al., 2017).

The prototypical alkylphosphate OP diisopropylfluorophosphate (DFP) was developed for the study of chemical weapons (Saunders, 1957). DFP is structurally homologous, but significantly less volatile, than nerve agents such as sarin, making DFP useful for investigating the mechanisms of sarin and other highly toxic OPs. Accordingly, DFP is one of the most widely studied OP alkylphosphates in the laboratory (Prendergast et al., 1997, 1998; Pope et al., 2005; Grigoryan et al., 2008; Nallapaneni et al., 2008; Wright et al., 2010; Terry et al., 2011, 2012; Ferchmin et al., 2015; Naughton et al., 2018; Naughton and Terry, 2018). Moreover, DFP is currently employed as an initiator of status epilepticus in seizure models (Deshpande et al., 2010; Todorovic et al., 2012; Pouliot et al., 2016) and a nerve agent surrogate in models of Gulf War Illness (O'Callaghan et al., 2015; Phillips et al., 2019). Nonetheless, there is a lack of information characterizing the cholinergic and noncholinergic mechanisms of Ops, such as DFP on hippocampal synaptic transmission. Though there is evidence of OPs inducing dorsoventral-specific pathology in the hippocampus (Apland et al., 2010), there are no reports in the literature investigating dorsoventral-specific effects of AChE inhibitors on hippocampal synaptic transmission. It is also unknown if dorsoventral-specific effects of AChE inhibitors are dependent on cholinergic and noncholinergic mechanisms resulting from the functional division of the two hippocampal sectors. Therefore, using a hippocampal slice preparation, the aim of the present work was to investigate the cholinergic and noncholinergic mechanisms that mediate the effects of DFP exposure on synaptic transmission in the $\mathrm{dH}$ and the $\mathrm{vH}$.

\section{Methods}

Animal Maintenance. Male C57BL/6J (Jackson Laboratory, Bar Harbor, ME) mice, aged 7-13 weeks, were housed in groups of five. Animals were acclimated to their home cages for at least 1 week after arrival and were maintained on a 12-hour light/dark cycle (lights on from 0700 to 1900 hours). Food and water were provided ad libitum. All experiments were performed in compliance with the University of Georgia Animal Care and Use Committee guidelines.

Slice Preparation and Electrophysiology. Hippocampal slice preparation and electrophysiology experiments were conducted as previously described (Keralapurath et al., 2017; Preston et al., 2019).
Briefly, mice were sacrificed following deep anesthetization with 2-bromo-2-chloro-1,1,1-trifluoroethane (halothane). Brains were removed and quickly submerged in oxygenated $\left(95 \% \mathrm{O}_{2} / 5 \% \quad \mathrm{CO}_{2}\right)$ ice-cold dissection artificial cerebrospinal fluid $(120 \mathrm{mM} \mathrm{NaCl}, 3 \mathrm{mM} \mathrm{KCl}$, $4 \mathrm{mM} \mathrm{MgCl}_{2}, 1 \mathrm{mM} \mathrm{NaH}_{2} \mathrm{PO}_{4}, 26 \mathrm{mM} \mathrm{NaHCO}_{3}$, and $10 \mathrm{mM}$ glucose). A mid-sagittal cut was made, and half of the brain was mounted on its caudal pole and sectioned along the horizontal plane with a vibratome to obtain $400-\mu \mathrm{m}$ slices containing the $\mathrm{dH}$. The other half of the brain was mounted on its rostral pole and sectioned along the horizontal plane with a vibratome to acquire $400-\mu \mathrm{m}$ slices containing the $\mathrm{vH}$. The $\mathrm{dH}$ and $\mathrm{vH}$ were subdissected free from the rest of the slice, and the CA3 subfield was removed. These slices were then quickly placed in a submersion-type chamber and perfused with oxygenated $(95 \%$ $\mathrm{O}_{2} / 5 \% \mathrm{CO}_{2}$ ) artificial cerebrospinal fluid (ACSF) $(120 \mathrm{mM} \mathrm{NaCl}, 3 \mathrm{mM}$ $\mathrm{KCl}, 1.5 \mathrm{mM} \mathrm{MgCl}_{2}, 1 \mathrm{mM} \mathrm{NaH}_{2} \mathrm{PO}_{4}, 2.5 \mathrm{mM} \mathrm{CaCl}_{2}, 26 \mathrm{mM} \mathrm{NaHCO}_{3}$, and $10 \mathrm{mM}$ glucose). Slices were continuously perfused with ACSF $(1 \mathrm{ml} / \mathrm{min}$ ) during a 45 -minute recovery period at room temperature followed by a 45-minute recovery period at the recording temperature of $30^{\circ} \mathrm{C}$. Schaffer collateral fibers were stimulated by placing a bipolar electrode (Kopf Instruments, Tujunga, CA) in the stratum radiatum of the CA1 subfield, whereas a $1.0 \mathrm{M} \Omega$ tungsten recording microelectrode (World Precision Instruments, Sarasota, FL) was inserted in the stratum pyramidale of CA1. During recording experiments, a stimulus pulse was applied once every minute to elicit responses from Schaffer Collateral-CA1 synapses.

A graphical representation of the experimental protocol is shown in Fig. 1A. A stimulus-response curve (I/O curve) was acquired at the beginning of each experiment by incrementally delivering single $20 \mu \mathrm{A}$ stimulus pulses ranging from 40 to $200 \mu \mathrm{A}$ in intensity and measuring the population spike (PS1) response (millivolts) from PS trough to PS peak. The stimulus intensity was adjusted to elicit ss that did not receive antagonist pretreatmen baseline responses of $75 \%$ of the maximal PS1 amplitude. Baseline paired-pulse ratio (PS-PPR) was then monitored each minute for 30 minutes via paired-pulse stimulation with an interpulse interval of $10 \mathrm{~ms}$. Baseline responses were recorded for 40 minutes during antagonist wash-in experiments. Antagonists were present for the entire duration of the experiment following 20 minutes of antagonist-free baseline recording. After establishing the baseline response, DFP was washed in to the bath for 30 minutes, and an I/O curve was immediately recorded at the end of the wash-in period. Slice PS-PPR was monitored for the following 1 hour. A final I/O curve was measured to determine the persisting effects of DFP exposure on basal synaptic transmission.

Determination of AChE Activity. Briefly, each assay was completed using $400 \mu \mathrm{m}$ individual $\mathrm{dH}$ or $\mathrm{vH}$ slices superfused with $1 \mathrm{ml} / \mathrm{min}$ ACSF $\pm \mathrm{DFP}$ for 4.75 hours \pm 15 minutes at $37^{\circ} \mathrm{C}$. Slices were immediately stored at $-80^{\circ} \mathrm{C}$ following completion of electrophysiology experiments. On the day of the assay, slices were kept frozen on dry ice until homogenized with Branson Sonifier 250 (Branson Ultrasonics, Danbury, CT) in ice-cold 0.05 M Tris-HCl ( $\mathrm{pH}$ 7.4) buffer. Sixty slices ( 30 from the $\mathrm{dH}$ and 30 from the $\mathrm{vH}$ ) were randomly selected for homogenization. Six slices from each sector $(\mathrm{dH}$ or $\mathrm{vH})$ and treatment level $(0,3,10,30$, and $100 \mu \mathrm{M} \mathrm{DFP})$ were prepared for the activity assay. AChE activity of each slice homogenate was measured in triplicate wells (three replicates/slice homogenate).

AChE activity was measured spectrophotometrically using a modification (Chambers et al., 1988; Chambers and Chambers, 1989) of Ellman et al. (1961), with acetylthiocholine as the substrate and 5,5'-dithio-bis(nitrobenzoic acid) as the chromogen. The method from Chambers et al. (1988) was scaled to a microplate format. Following

Baseline was then monitored for an additional 20 minutes (40 minutes total baseline). Slices that did not receive antagonist pretreatment ( $\square$ ) and slices that received antagonist pretreatment (-) were exposed to DFP as indicated by the arrow at 40 minutes. Representative traces are shown for antagonist experiments in which the baseline PS1 (gray) and the PS1 following 60 minutes DFP wash-out (black) are shown. Reported $n$ values $[x(y)]$ indicate the number of slices $(x)$ and the number of mice $(y)$ assessed. Data are expressed as mean \pm S.E.M. 
A

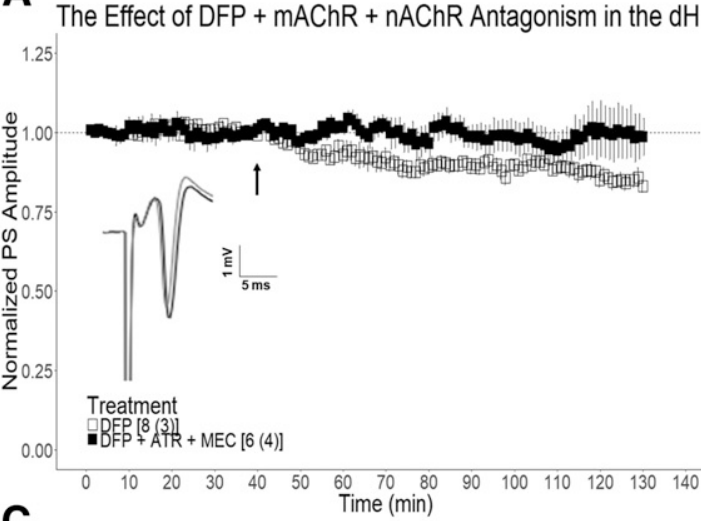

C

Effect of DFP $+\mathrm{M}_{2} \mathrm{R}+\mathrm{nAChR}+\mathrm{NMDAR}$ Antagonism in the $\mathrm{dH}$

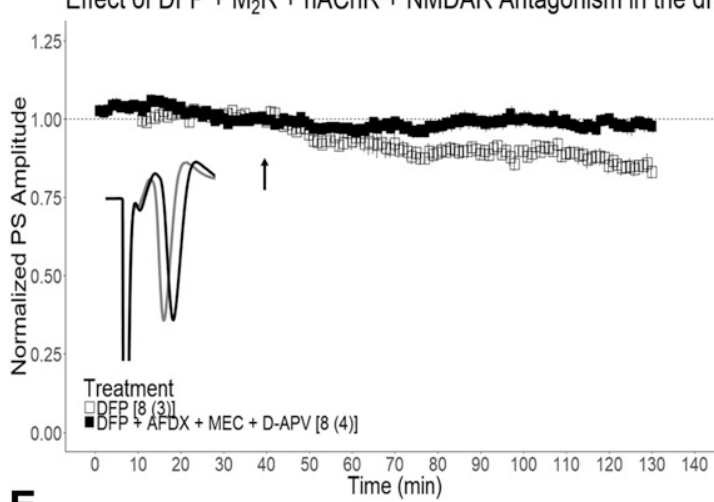

E

The Effect of $30 \mu M$ DFP + NMDAR Antagonism in the $\mathrm{dH}$

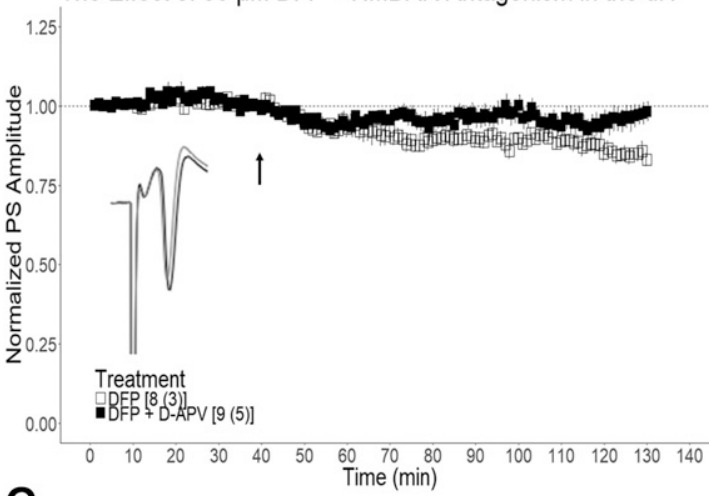

G The Effect of $30 \mu \mathrm{M} D F P+$ RyR Antagonism in the $\mathrm{dH}$

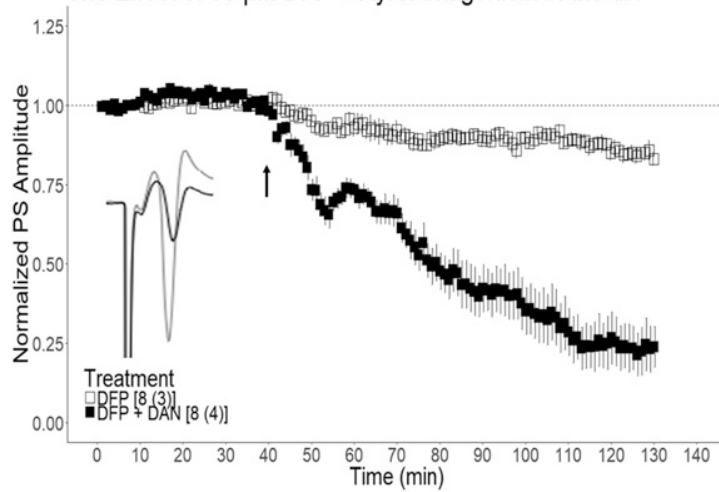

The Effect of DFP + mAChR + nAChR Antagonism in the vH

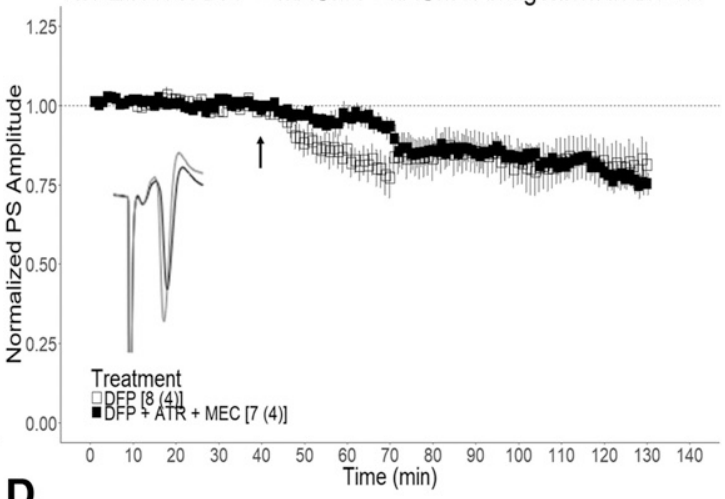

Effect of DFP $+\mathrm{M}_{2} \mathrm{R}+\mathrm{nAChR}+\mathrm{NMDAR}$ Antagonism in the $\mathrm{vH}$

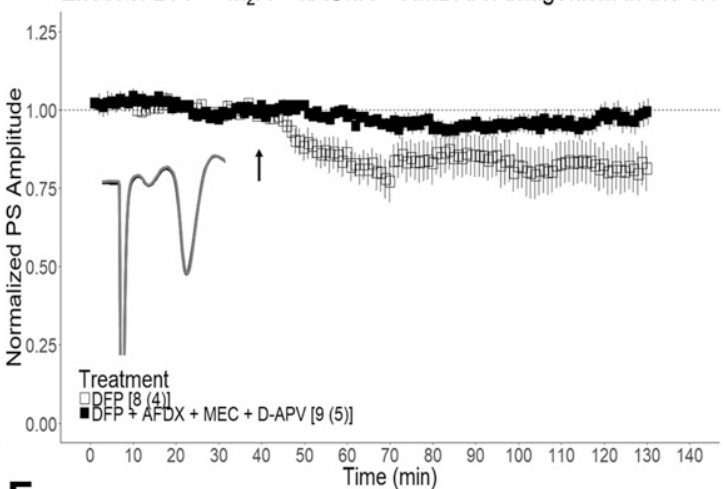

$\mathbf{F}$

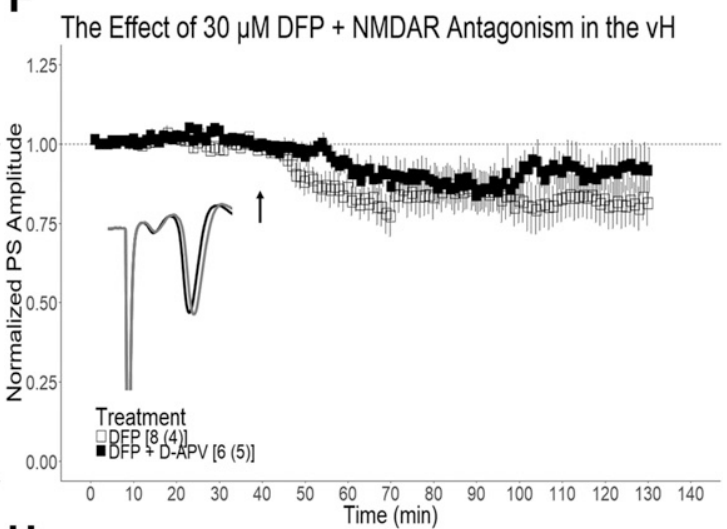

H

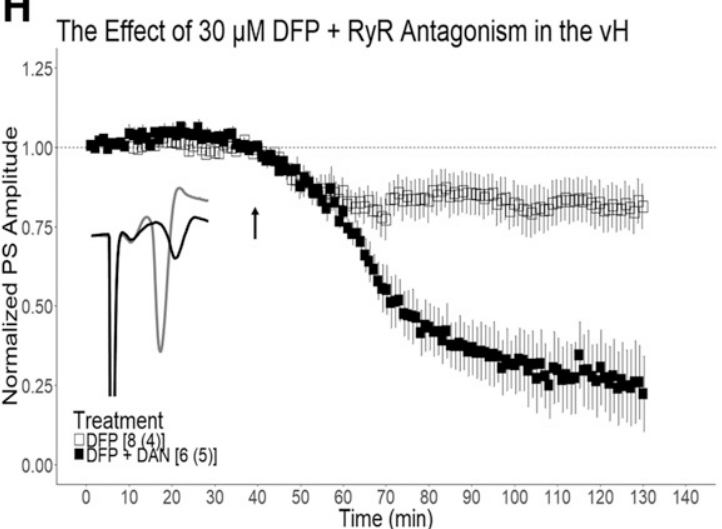

Fig. 3. Either cholinergic or NMDAR blockade is sufficient in preventing DFP-mediated PS1 inhibition in the dH, but NMDAR blockade is indispensable in the $\mathrm{vH}$. (A and B) The effect of $3 \mu \mathrm{M}$ atropine (ATR) and $30 \mu \mathrm{M}$ mecamylamine (MEC) pretreatment on $30 \mu \mathrm{M}$ DFP-mediated PS1 inhibition in the $\mathrm{dH}(\mathrm{A})$ and the $\mathrm{vH}(\mathrm{B})$. (C and D) The effect of $300 \mathrm{nM}$ AFDX-116, $30 \mu \mathrm{M}$ MEC, and $25 \mu \mathrm{M}$ D-APV pretreatment on $30 \mu \mathrm{M}$ DFP-mediated PS1 inhibition in the $\mathrm{dH}(\mathrm{C})$ and the $\mathrm{vH}(\mathrm{D})$. ( $\mathrm{E}$ and $\mathrm{F}$ ) The effect of $25 \mu \mathrm{M}$ D-APV pretreatment on $30 \mu \mathrm{M}$ DFP-mediated PS1 inhibition in the dH (E) and the $\mathrm{vH}(\mathrm{F})$. (G and $\mathrm{H}$ ) The effect of $20 \mu \mathrm{M}$ dantrolene (DAN) pretreatment on $30 \mu \mathrm{M}$ DFP-mediated PS1 inhibition in the $\mathrm{dH}(\mathrm{G})$ and the $\mathrm{vH}(\mathrm{H})$. Slices 
20-minute incubation of each slice homogenate with the reaction mixture described in Chambers et al. (1988), absorbance was measured via BioTek Epoch Microplate spectrophotometer at $412 \mathrm{nM}$. An AChE standard curve was included alongside the samples at the following concentrations: $0,1,3,10,30,100,300$, and $1000 \mathrm{mU} / \mathrm{ml}$ [diluted in $0.05 \mathrm{M}$ Tris- $\mathrm{HCl}$ ( $\mathrm{pH}$ 7.4) buffer; AChE source: Electrophorus electricus (Sigma-Aldrich, St. Louis, MO)]. Physostigmine hemisulfate $(10 \mu \mathrm{M})$ was incubated with a subset of control samples to serve as the positive control. AChE enzyme activity was normalized on a per-milligram of tissue protein basis. Protein content in the homogenized samples was quantified via the Bradford protein assay method (Bradford, 1976) in a 96-well plate using Bradford reagent from Bio-Rad (Hercules, CA). Bovine serum albumin (Fisher Scientific, Pittsburgh, PA) was used as the standard for the protein quantification assay.

Drugs. AFDX-116(11-[[2-[(Diethylamino)methyl]-1-piperidinyl]acetyl]-5,11-dihydro-6H-pyrido[2,3-b][1,4]benzodiazepin-6-one), atropine sulfate, acetylthiocholine iodide, acetylcholinesterase, 5,5'-dithiobis(nitrobenzoic acid), and diisopropylfluorophosphate (Purity: 99\%, Lot: MKCD1107) were purchased from Sigma-Aldrich. Dantrolenesodium, D-(-)-2-Amino-5- phosphonopentanoic acid (D-APV), mecamylamine $\mathrm{HCl}$, and physostigmine hemisulfate were purchased from Tocris Bioscience (Minneapolis, MN). Pirenzepine was purchased from Alfa Aesar (Tewksbury, MA). A total of $2.5 \mathrm{mM}$ AFDX-116 and $20 \mathrm{mM}$ dantrolene (DAN) stock solutions were prepared in DMSO. Then, $0.1 \%$ DMSO vehicle control experiments were conducted to confirm that DMSO did not induce a significant effect on population spike responses.

Data Analysis. Electrophysiology data were digitized at $10 \mathrm{kHz}$, low-pass filtered at $1 \mathrm{kHz}$, and analyzed with pCLAMP 10.2 software (Axon Instruments, Sunnyvale, CA). Synaptic responses of the first PS (PS1) were normalized to one using the average PS1 amplitude of the last 5 minutes of baseline. Thirty-minute DFP wash-in and 60 -minute DFP wash-out PS1 values were calculated using the average PS1 amplitude values 26-30 minutes after beginning DFP wash in and 56-60 minutes into DFP wash-out, respectively. The effect of an antagonist on the PS1 was evaluated by comparing the average PS1 amplitude of the last 5 minutes prior to antagonist wash-in (16-20 minutes) compared with the average PS1 amplitude of the last 5 minutes prior to DFP wash-in (36-40 minutes). PS-PPR values were obtained by pairing a conditioning stimulus, which evoked PS1, with a second stimulus, evoking PS2, and calculating the percent change of PS2 with respect to PS1 (PS-PPR = PS2/PS1).

Reported $n$ values $[x(y)]$ indicate the number of slices $(x)$ and the number of mice $(y)$ assessed. All statistical analyses and graphic production were completed using $\mathrm{R}$ version 3.3.2 (The $\mathrm{R}$ Foundation for Statistical Computing, Vienna, Austria). Statistical analysis was completed by using the aov() function for analysis of variance (ANOVA) and the t.test function for the Student's $t$ test. Graphic production was completed via R package "ggplot2." DFP dose-response curve statistical analysis was conducted via one-way repeated measures ANOVA followed by Dunnett's multiple comparison test. The Student's $t$ test (one-tailed) was used for all other pairwise comparisons of data. An $\alpha$ level of 0.05 was used as the criterion for statistical significance. All data are presented as mean \pm S.E.M.

\section{Results}

Population Spike Inhibition and Concurrent Population Spike Paired-Pulse Facilitation Were Observed in Dorsal and Ventral Hippocampal Slices Following DFP Wash-In. A significant main effect of DFP exposure on the PS1 amplitude was observed in the $\mathrm{dH}(\mathrm{F} 4,39=38.2$,
$P<0.001)$ and the vH $(\mathrm{F} 4,38=46.6, P<0.001$; Fig. 1 , B and C, respectively). A Dunnett's multiple comparison test revealed significant inhibition of the PS1 amplitude in $\mathrm{dH}(P<0.05)$ and $\mathrm{vH}(P<0.001)$ slices exposed to $30 \mu \mathrm{M}$ DFP compared with unexposed slices. Additionally, Dunnett's test revealed that $100 \mu \mathrm{M}$ DFP wash-in induced significant PS1 inhibition in $\mathrm{dH}(P<0.001)$ and $\mathrm{vH}$ slices $(P<0.001)$ compared with unexposed slices. Interestingly, marginal (nonsignificant) recovery of the PS1 amplitude was observed in both $\mathrm{dH}$ and $\mathrm{vH}$ slices treated with $100 \mu \mathrm{M}$ DFP. $\mathrm{dH}$ and $\mathrm{vH}$ slices that were not exposed to DFP displayed no significant change in PS1 amplitude approximately 2 hours after establishing baseline. A one-way ANOVA (DFP treatment as a factor) revealed a significant main effect of DFP on AChE activity, indicating that $\mathrm{dH}$ and $\mathrm{vH}$ slices exposed to DFP exhibited a significant reduction in AChE activity (F4,55 $=15.2, P<0.001$; IC50 = $2.70 \mu \mathrm{M}$; Fig. 1, D and E). dH and vH slices were combined in AChE activity assay analyses, as a two-way ANOVA (sector and DFP treatment as factors) revealed no significant main effect of hippocampal sector on AChE activity (F1,50 $=0.0220$, $P=0.88$ ). Based on these results, $30 \mu \mathrm{M}$ DFP was used as the DFP concentration for all remaining experiments throughout this study.

Nonselective nAChR Antagonism Enhances DFPMediated Population Spike Inhibition in the Dorsal and the Ventral Hippocampus. The nonselective, noncompetitive $\mathrm{nAChR}$ antagonist mecamylamine (MEC) was employed to investigate the role of the nAChR in DFPmediated PS1 inhibition. Pretreatment with $30 \mu \mathrm{M}$ MEC significantly enhanced DFP-mediated PS1 inhibition in the $\mathrm{dH}[\mathrm{t}(17)=2.00, P=0.031]$ and the $\mathrm{vH}[\mathrm{t}(15)=1.86$, $P=0.042$ ] compared with $30 \mu \mathrm{M}$ DFP alone (Fig. 2, A and B, respectively). Furthermore, significantly enhanced PS1 inhibition in the $\mathrm{dH}[\mathrm{t}(17)=2.77, P=0.0066]$ and the $\mathrm{vH}[\mathrm{t}(15)$ $=4.26, P<0.001]$ was observed following 60 minutes DFP wash-out. The magnitude of PS1 inhibition in $\mathrm{dH}$ slices treated with DFP and MEC was significantly less than the inhibition observed in the $\mathrm{vH}$ after 30 minutes DFP wash-in $[\mathrm{t}(18)=2.74, P=0.0068]$ and 60 minutes DFP wash-out $[\mathrm{t}(18)$ $=2.82, P=0.0057]$. MEC alone did not induce a significant effect on PS1 amplitude in the $\mathrm{dH}$ or the $\mathrm{vH}$.

Nonselective mAChR Blockade Prevents DFP-Mediated Population Spike Inhibition in the Dorsal Hippocampus but Not in the Ventral Hippocampus. The nonselective mAChR antagonist atropine (ATR) was selected to investigate the role of the mAChR in DFP-mediated PS1 inhibition. Preexposure to $3 \mu \mathrm{M}$ ATR prevented DFP-mediated PS1 inhibition the $\mathrm{dH}[\mathrm{t}(13)=3.32, P=0.0027$; Fig. $2 \mathrm{C}]$. Interestingly, PS1 in the $\mathrm{dH}$ was enhanced following 60 minutes DFP wash-out $[\mathrm{t}(13)=4.11, P<0.001]$. Conversely, ATR pretreatment prevented DFP-induced PS1 inhibition in the vH after 30-minute application of DFP [t(15) $=2.20, P=0.022]$, but this effect did not persist following 60 minutes DFP wash-out [ $\mathrm{t}(15)=0.0941$, $P=0.46$; Fig. 2D]. The magnitude of PS1 inhibition between $\mathrm{dH}$ and $\mathrm{vH}$ slices treated with DFP and ATR was significantly different after 30 minutes DFP wash-in [t(14) $=3.41, P=0.0021]$

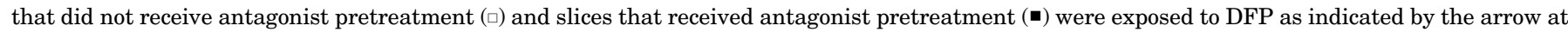

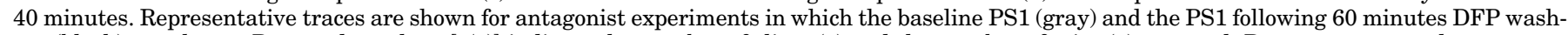

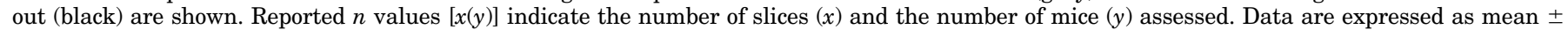
S.E.M. 
A The Effect of $30 \mu \mathrm{M}$ DFP + nAChR Antagonism in the $\mathrm{dH}$

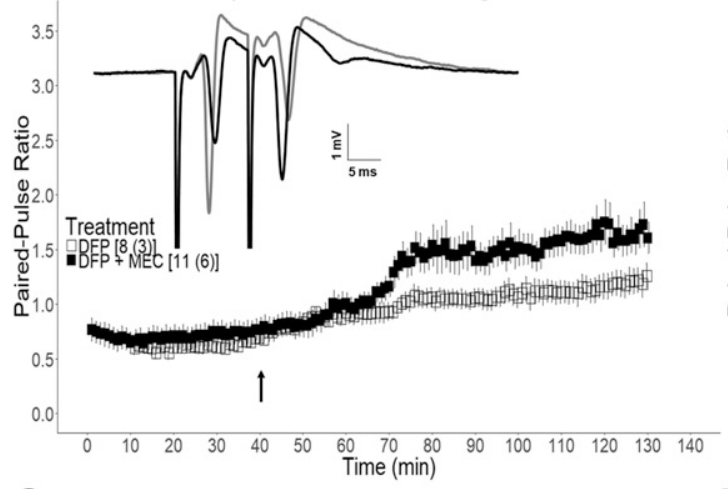

C

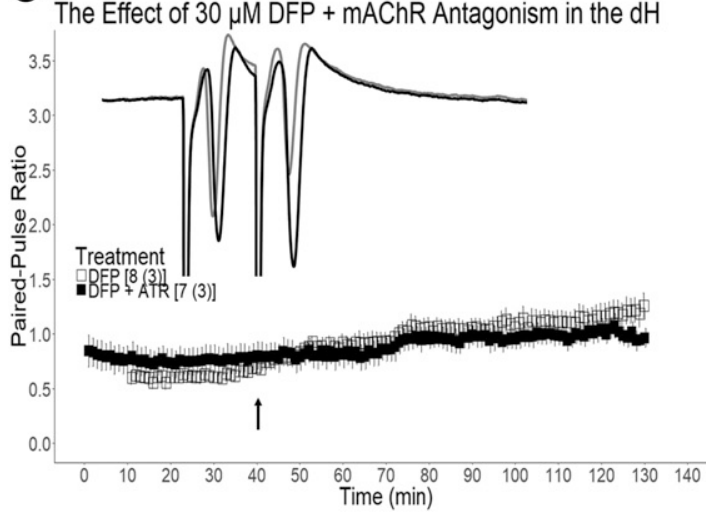

E

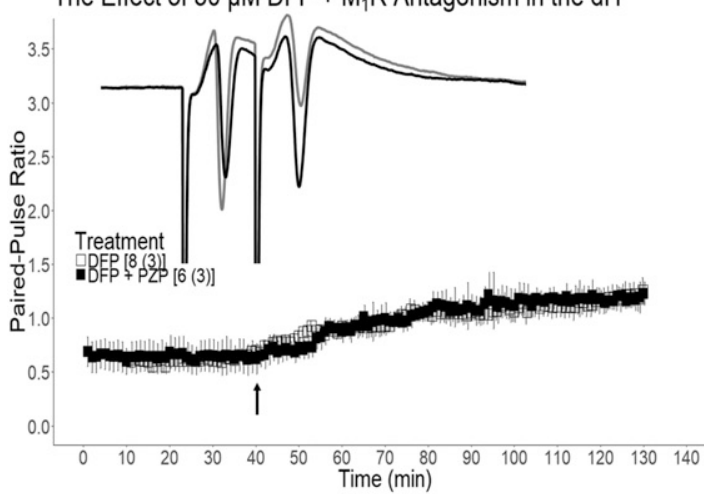

G

The Effect of $30 \mu \mathrm{M}$ DFP $+\mathrm{M}_{2} \mathrm{R}$ Antagonism in the $\mathrm{dH}$

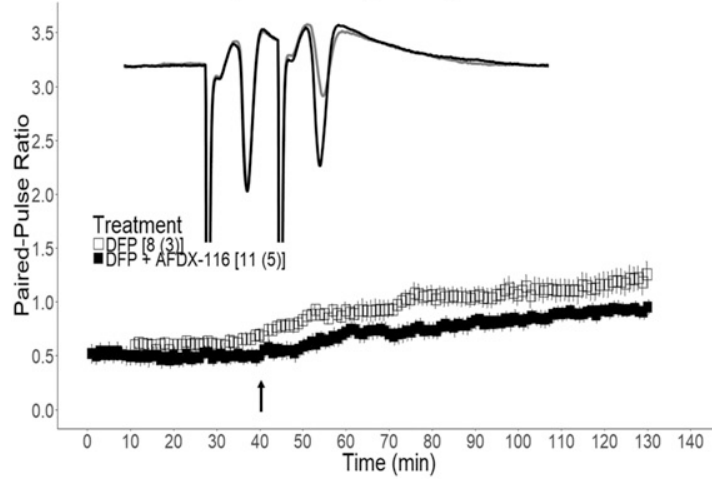

B The Effect of $30 \mu \mathrm{M}$ DFP + nAChR Antagonism in the $\mathrm{vH}$

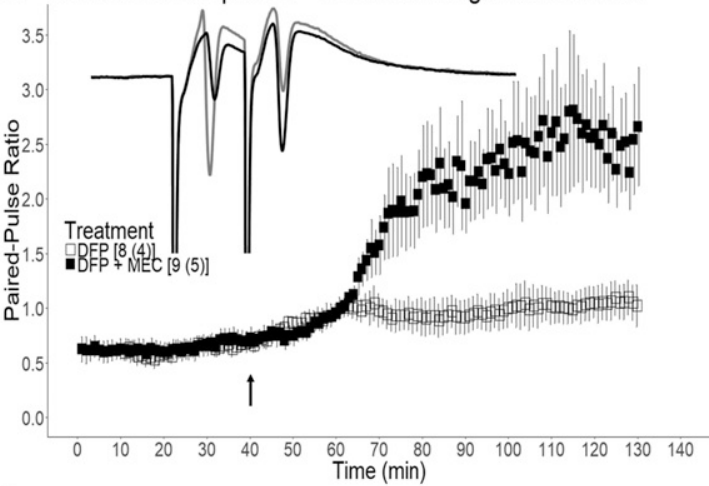

D
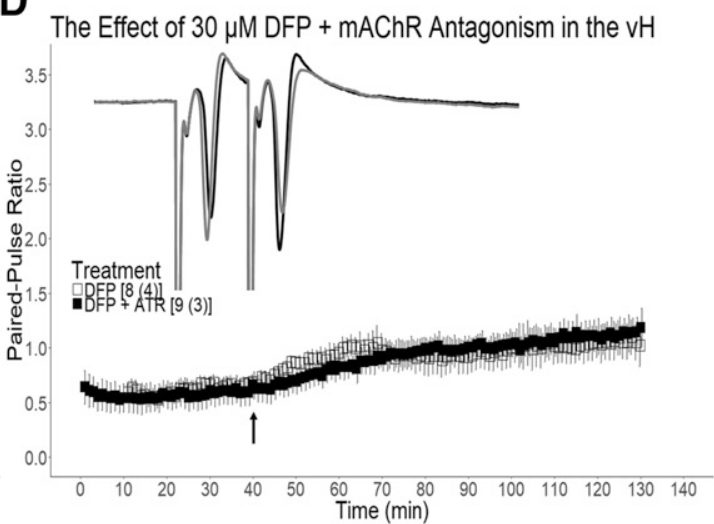

$\mathbf{F}$

The Effect of $30 \mu \mathrm{M} D F P+M_{1} R$ Antagonism in the $v H$

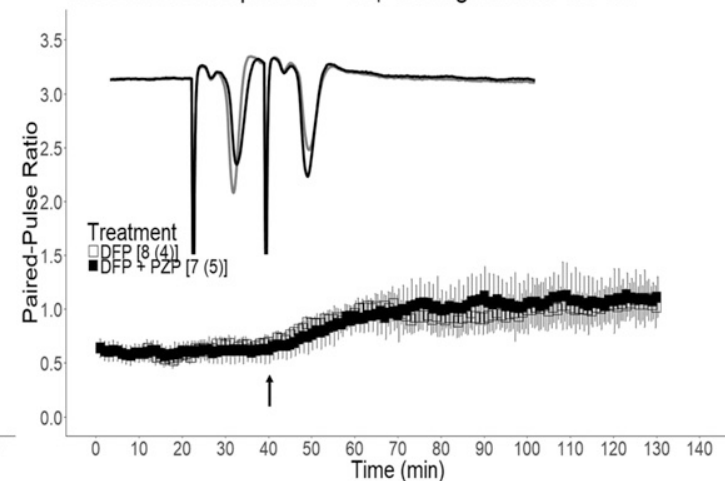

H

The Effect of $30 \mu M$ DFP $+\mathrm{M}_{2} \mathrm{R}$ Antagonism in the $\mathrm{vH}$

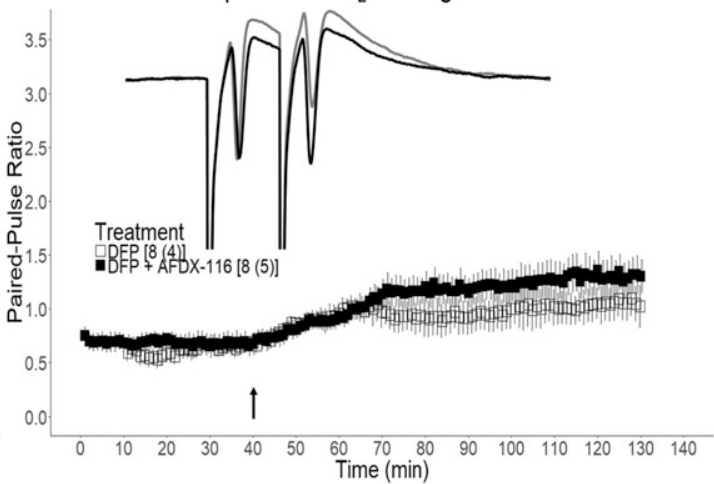

Fig. 4. Cholinergic antagonist pretreatment does not preserve population spike paired- pulse inhibition (PS-PPI) in either $\mathrm{dH}$ or vH slices exposed to DFP. (A and B) The effect of $30 \mu \mathrm{M}$ mecamylamine (MEC) pretreatment on $30 \mu \mathrm{M}$ DFP-mediated population spike paired-pulse ratio (PS-PPR) modulation in the $\mathrm{dH}(\mathrm{A})$ and the $\mathrm{vH}(\mathrm{B})$. (C and D) The effect of $3 \mu \mathrm{M}$ atropine (ATR) pretreatment on $30 \mu \mathrm{M}$ DFP-mediated PS-PPR modulation in the $\mathrm{dH}(\mathrm{C})$ and the $\mathrm{vH}(\mathrm{D})$. (E and F) The effect of $100 \mathrm{nM}$ pirenzepine (PZP) pretreatment on $30 \mu \mathrm{M}$ DFP-mediated PS-PPR modulation in the dH (E) and the $\mathrm{vH}(\mathrm{F}) .(\mathrm{G}$ and $\mathrm{H})$ The effect of $300 \mathrm{nM}$ AFDX-116 pretreatment on $30 \mu \mathrm{M}$ DFP-mediated PS-PPR modulation in the $\mathrm{dH}(\mathrm{G})$ and the $\mathrm{vH}(\mathrm{H})$. Slices that did 
and 60 minutes DFP wash-out [t(14) $=2.64, P=0.0097]$. ATR alone did not induce a significant effect on PS1 amplitude in the $\mathrm{dH}$ or the $\mathrm{vH}$.

Selective M2 mAChR, but Not M1 mAChR, Blockade Prevents DFP-Mediated Population Spike Inhibition in the Dorsal Hippocampus but Not in the Ventral Hippocampus. Pretreatment of slices with $100 \mathrm{nM}$ of the M1 $\mathrm{mAChR}$ selective antagonist pirenzepine (PZP) did not prevent DFP-mediated PS1 inhibition in either the $\mathrm{dH}[\mathrm{t}(12)=$ $0.645, P=0.27]$ or the $\mathrm{vH}[\mathrm{t}(13)=0.126, P=0.45$; Fig. 2 , E and F, respectively]. Pretreatment with 300 nM AFDX-116, a selective M2 mAChR (M2R) antagonist, prevented DFPmediated PS1 inhibition in the $\mathrm{dH}[\mathrm{t}(17)=2.01, P=0.030$; Fig. 2G]. Strikingly, PS1 in the $\mathrm{dH}$ quantitatively resembled the enhancement observed in ATR experiments following 60 minutes DFP wash-out [t(17) $=3.08, P=0.0034]$. Conversely, AFDX-116 pretreatment had no significant effect on DFP-induced PS1 inhibition in the $\mathrm{vH}$ after 30 -minute application of DFP $[\mathrm{t}(14)=1.02, P=0.16]$ nor after 60 minutes DFP wash-out $[\mathrm{t}(14)=0.277, P=0.39$; Fig. $2 \mathrm{H}]$. The magnitude of PS1 inhibition in $\mathrm{dH}$ and $\mathrm{vH}$ slices treated with DFP and AFDX-116 was significantly different following 30 minutes DFP wash-in $[\mathrm{t}(17)=2.27, P=0.018]$ and 60 minutes DFP wash-out $[\mathrm{t}(17)=3.02, P=0.0039]$. Neither PZP nor AFDX-116 alone induced a significant effect on PS1 amplitude in the $\mathrm{dH}$ or the $\mathrm{vH}$.

Concurrent Nonselective mAChR and nAChR Blockade Prevents DFP-Mediated Population Spike Inhibition in the Dorsal Hippocampus but Not in the Ventral Hippocampus. Coapplication of $3 \mu \mathrm{M}$ ATR and $30 \mu \mathrm{M}$ MEC to $\mathrm{dH}$ slices prior to wash-in of DFP prevented the DFPmediated PS1 inhibition after 30 minutes of DFP application $[\mathrm{t}(12)=2.18, P=0.025]$ and 60 minutes of DFP wash-out $[\mathrm{t}(12)=2.16, P=0.026$; Fig. 3A]. The DFP-mediated PS1 inhibition was significantly prevented in the $\mathrm{vH}$ following 30 minutes of DFP application $[\mathrm{t}(13)=2.09, P=0.028$ ], but the effect of cholinergic antagonist pretreatment did not persist following a 60-minute DFP wash-out period $[\mathrm{t}(13)=$ $0.649, P=0.26$; Fig. 3B]. The dorsoventral-specific effect of DFP-mediated PS1 inhibition observed in previous cholinergic antagonist experiments was also observed in ATR and MEC coapplication experiments, in which dH PS1 was significantly greater than vH PS1 following 30 minutes DFP wash-in $[\mathrm{t}(11)=1.80, P=0.049]$ and 60 minutes DFP wash-out $[\mathrm{t}(11)=2.96, P=0.0065]$. Coapplication of ATR and MEC did not induce a significant effect on PS1 amplitude in the $\mathrm{dH}$ or the $\mathrm{vH}$.

M2R, N-methyl-D-aspartate receptor, and Nonselective nAChR Blockade Prevents DFP-Mediated Population Spike Inhibition in the Dorsal and the Ventral Hippocampus. Coapplication of $300 \mathrm{nM}$ AFDX-116, $25 \mu \mathrm{M}$ D-APV [an N-methyl-D-aspartate receptor (NMDAR) competitive antagonist], and $30 \mu \mathrm{M}$ MEC prior to wash-in of DFP resulted in no observable effect of DFP on the PS1 in the $\mathrm{dH}$ $[\mathrm{t}(14)=1.89, P=0.040]$ or the $\mathrm{vH}[\mathrm{t}(15)=2.86, P=0.0059$; Fig. 3, C and D, respectively]. Prevention of DFP-mediated
PS1 inhibition persisted in the $\mathrm{dH}[\mathrm{t}(14)=4.42, P<0.001]$ and the $\mathrm{vH}[\mathrm{t}(15)=2.12, P=0.026]$ following 60 minutes of DFP wash-out. The dorsoventral-specific effect of DFPmediated PS1 inhibition that was present in cholinergic antagonist pretreatment experiments was not observed in this triple antagonist wash-in experiment following 30 minutes DFP wash-in [t(15) $=0.808, P=0.22]$ and 60 minutes DFP wash-out $[\mathrm{t}(15)=0.124, P=0.45]$. Coapplication of AFDX-116, D-APV, and MEC did not induce a significant effect on PS1 amplitude in the $\mathrm{dH}$ or the $\mathrm{vH}$. These data and those previously shown suggest that DFP-induced PS1 inhibition is mediated by the M2R in the $\mathrm{dH}$, whereas the effect of DFP is mediated by both cholinergic receptors and the NMDAR in the vH.

NMDAR Antagonism Prevents DFP-Mediated Population Spike Inhibition in the Dorsal and the Ventral Hippocampus. Pretreatment of $\mathrm{dH}$ slices with $25 \mu \mathrm{M}$ D-APV did not significantly prevent DFP-mediated PS1 inhibition following 30 minutes DFP wash-in [t(15) $=1.33, P=$ 0.10]; however, a significant reduction in PS1 inhibition was observed following 60 minutes DFP wash-out $[\mathrm{t}(15)=3.12$, $P=0.0035$; Fig. 3E]. D-APV pretreatment of $\mathrm{vH}$ slices did not significantly prevent DFP-mediated PS1 inhibition compared with slices that received DFP alone following 30 minutes DFP wash-in [t(12) $=1.24, P=0.12]$ or 60 minutes DFP wash-out $[\mathrm{t}(12)=1.05, P=0.15$; Fig. $3 \mathrm{~F}]$; however, vH slices pretreated with D-APV did not display a significantly different PS1 amplitude compared with control vH slices at the 30-minute DFP wash-in $[\mathrm{t}(15)=1.69, P=0.56]$ or the 60 -minute DFP wash-out time point [t(15) $=0.421, P=0.34]$. Interestingly, the magnitude of DFP-induced PS1 inhibition was not significantly different in the $\mathrm{dH}$ compared with the $\mathrm{vH}$ following 30 minutes DFP wash-in $[\mathrm{t}(13)=1.56, P=0.072]$ and 60 minutes DFP wash-out $[\mathrm{t}(13)=0.692, P=0.25]$ when D-APV was present in the bath. Prior to DFP application, D-APV alone did not induce a significant effect on PS1 amplitude in the $\mathrm{dH}$ or the $\mathrm{vH}$ (Supplemental Fig. 2, A and $\mathrm{B}$, respectively).

Ryanodine Receptor Antagonism Enhances DFP-Mediated Population Spike Inhibition in the Dorsal and the Ventral Hippocampus. As the NMDAR is involved in hippocampal $\mathrm{Ca}^{2+}$-induced $\mathrm{Ca}^{2+}$ release, we investigated the role of intracellular $\mathrm{Ca}^{2+}\left(\left[\mathrm{Ca}^{2+}\right] \mathrm{i}\right)$ stores in DFP-mediated PS1 inhibition by blocking ryanodine receptors (RyRs). Pretreatment with $20 \mu \mathrm{M}$ DAN significantly enhanced DFP-mediated PS1 inhibition in the $\mathrm{dH}[\mathrm{t}(14)=4.88$, $P<0.001]$ and the vH $[\mathrm{t}(12)=2.44, P=0.016]$ compared with $30 \mu \mathrm{M}$ DFP alone (Fig. $3, \mathrm{G}$ and $\mathrm{H}$, respectively). Furthermore, inhibition of the PS1 in the $\mathrm{dH}[\mathrm{t}(14)=8.11$, $P<0.001]$ and the vH $[\mathrm{t}(12)=4.33, P<0.001]$ was significantly enhanced following 60 minutes DFP wash-out. There was no significant difference in PS1 inhibition in $\mathrm{dH}$ and $\mathrm{vH}$ slices pretreated with DAN after 30 minutes DFP wash-in $[\mathrm{t}(12)=1.07, P=0.15]$ and 60 minutes DFP wash-out $[\mathrm{t}(12)=0.117, P=0.45]$. DAN alone did not induce a significant effect on PS1 amplitude in the $\mathrm{dH}$ or the $\mathrm{vH}$.

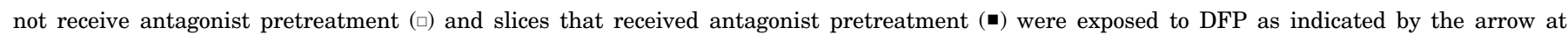

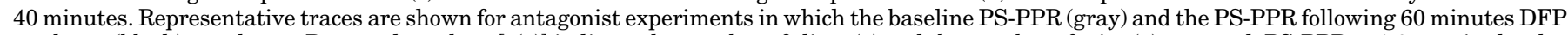

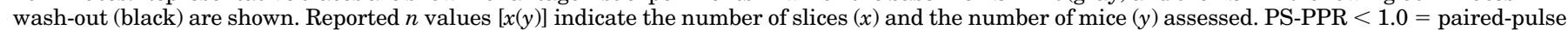
inhibition (PS-PPI); PS-PPR $>1.0=$ paired-pulse facilitation (PS-PPF). Data are expressed as mean \pm S.E.M. 
A The Effect of DFP + mAChR + nAChR Antagonism in the $\mathrm{dH}$

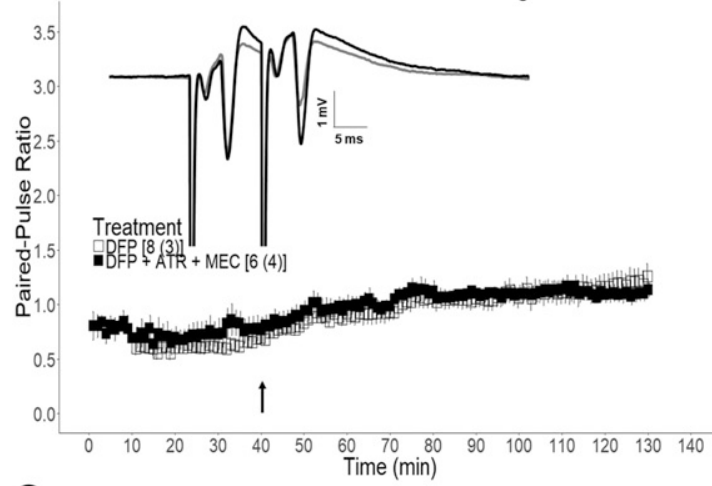

C

Effect of DFP $+\mathrm{M}_{2} \mathrm{R}+\mathrm{nAChR}+\mathrm{NMDAR}$ Antagonism in the $\mathrm{dH}$

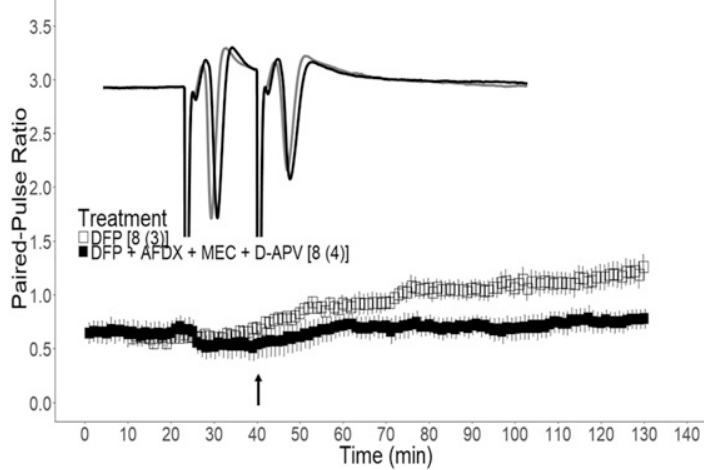

E

The Effect of $30 \mu \mathrm{M}$ DFP + NMDAR Antagonism in the $\mathrm{dH}$

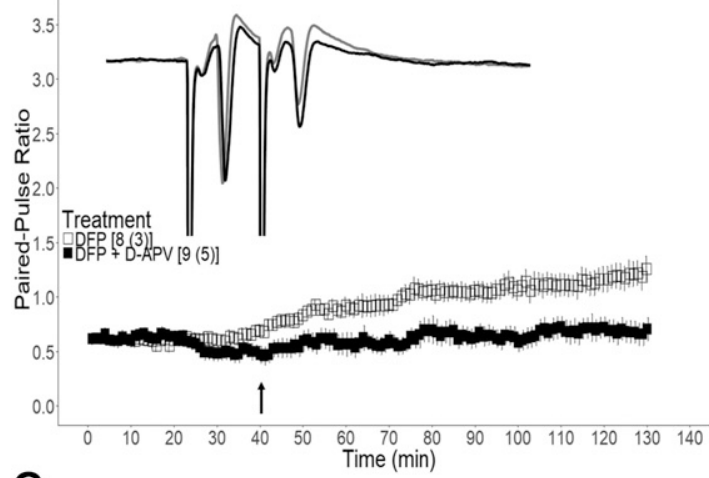

G

The Effect of $30 \mu \mathrm{M}$ DFP + RyR Antagonism in the $\mathrm{dH}$

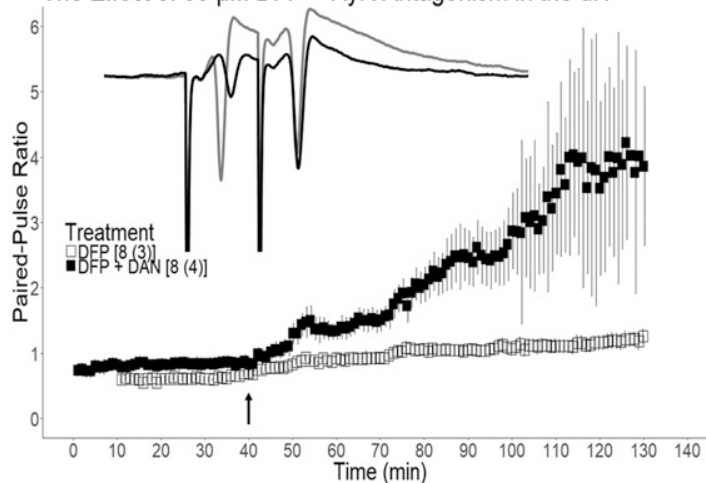

B The Effect of DFP + mAChR + nAChR Antagonism in the $\mathrm{vH}$

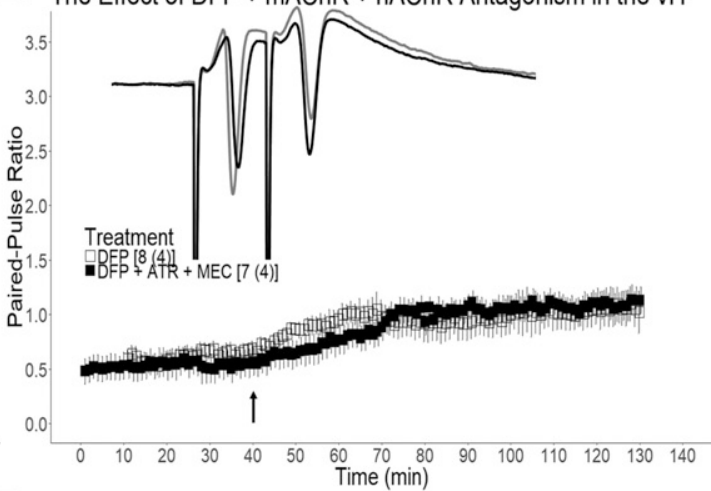

D

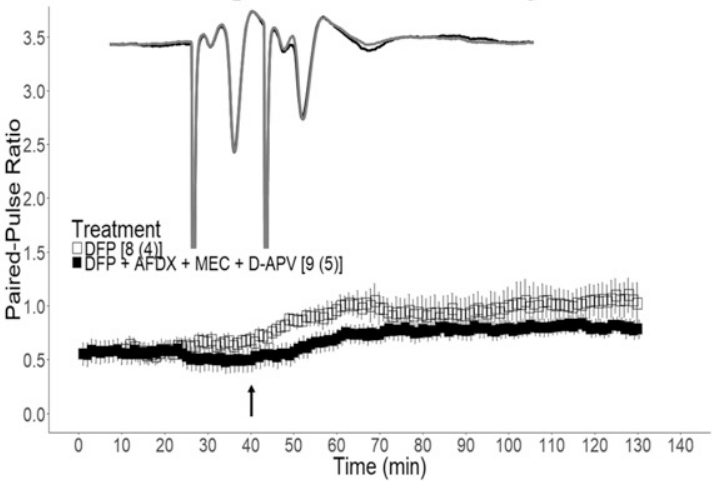

$\mathbf{F}$

The Effect of $30 \mu M$ DFP + NMDAR Antagonism in the $\mathrm{vH}$

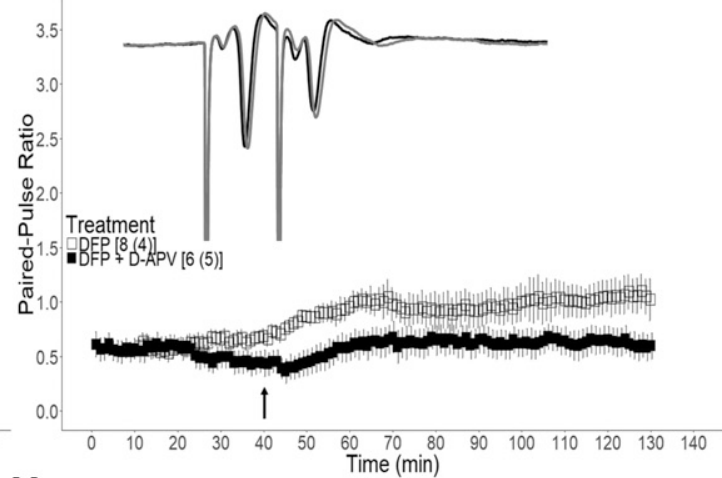

H

The Effect of $30 \mu M$ DFP + RyR Antagonism in the $\mathrm{vH}$

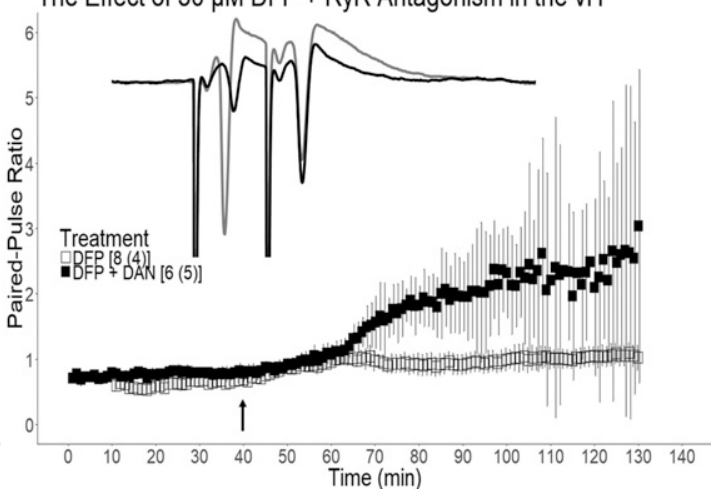

Fig. 5. NMDAR antagonist pretreatment preserves PS-PPI in $\mathrm{dH}$ and $v H$ slices exposed to DFP. (A and B) The effect of $3 \mu \mathrm{M}$ atropine (ATR) and $30 \mu \mathrm{M}$ mecamylamine (MEC) pretreatment on $30 \mu \mathrm{M}$ DFP-mediated population spike paired-pulse ratio (PS-PPR) modulation in the dH (A) and the vH (B), $(\mathrm{C}$ and D) The effect of $300 \mathrm{nM}$ AFDX-116, $30 \mu \mathrm{M}$ MEC, and $25 \mu \mathrm{M}$ D-APV pretreatment on $30 \mu \mathrm{M}$ DFP-mediated PS-PPR modulation in the dH (C) and the $\mathrm{vH}(\mathrm{D})$. (E and F) The effect of $25 \mu \mathrm{M}$ D-APV pretreatment on $30 \mu \mathrm{M}$ DFP-mediated PS-PPR modulation in the $\mathrm{dH}(\mathrm{E})$ and the $\mathrm{vH}(\mathrm{F})$. (G and $\mathrm{H})$ The effect of $20 \mu \mathrm{M}$ dantrolene (DAN) pretreatment on $30 \mu \mathrm{M}$ DFP-mediated PS-PPR modulation in the dH $(\mathrm{G})$ and the $\mathrm{vH}(\mathrm{H})$. Slices that did not receive 
Population Spike Paired-Pulse Facilitation Observed in Dorsal and Ventral Hippocampus Slices Exposed to DFP Is Mediated by a Noncholinergic Mechanism. The PS-PPR recorded from control dH and $\mathrm{vH}$ slices initially exhibit PS paired-pulse inhibition (PS-PPI, ratio $<1.0$ ), an indicator of functional recurrent inhibition $(\mathrm{RI})$ in the CA1 subfield (Supplemental Fig. 1, A and B). Following $30 \mu \mathrm{M}$ DFP treatment, PS paired-pulse facilitation (PS-PPF, ratio $>1.0)$ in the $\mathrm{dH}[\mathrm{t}(7)=3.00, P=0.010]$ and the $\mathrm{vH}[\mathrm{t}(7)=$ 3.29, $P=0.0067$ ] was observed (Fig. 4, A and B). Persisting PS-PPF was observed in the $\mathrm{dH}[\mathrm{t}(7)=4.26, P=0.0019]$ and the $\mathrm{vH}[\mathrm{t}(7)=3.20, P=0.0075]$ following DFP wash-out. DH $[\mathrm{t}(6)=0.380, P=0.36]$ and $\mathrm{vH}[\mathrm{t}(10)=1.34, P=0.11]$ slices that were not exposed to DFP displayed no significant change in PS-PPR approximately 2 hours after establishing baseline (data not shown). Pretreatment of $\mathrm{dH}$ slices with the nAChR antagonist MEC resulted in significantly enhanced PS-PPR compared with slices that received DFP alone $[\mathrm{t}(17)=1.84 P=$ 0.040; Fig. 4A]. Likewise, pretreatment of vH slices with MEC resulted in significantly enhanced PS-PPR compared with slices that received DFP alone $[\mathrm{t}(15)=2.60 P=0.010$; Fig. 4B]. DH slices pretreated with the mAChR antagonist ATR did not exhibit significantly different PS-PPR $[\mathrm{t}(13)=$ $0.958, P=0.18$ ] from slices that received only DFP (Fig. 4C). Moreover, we did not observe a significant difference in PS-PPR in $\mathrm{vH}$ slices pretreated with ATR compared with those that received DFP alone [t(15) $=1.38, P=0.09$; Fig. 4D]. Pre-exposure of $\mathrm{dH}$ slices to the M1 mAChR selective antagonist PZP did not prevent the significant increase of PS-PPR observed following DFP wash-in $[\mathrm{t}(12)=0.0937, P=0.46$; Fig. 4E]. Likewise, pre-exposure of $\mathrm{vH}$ slices to PZP did not prevent the significant increase of PS-PPR after DFP wash-in $[\mathrm{t}(13)=0.0622, P=0.48$; Fig. $4 \mathrm{~F}]$. However, dH slices that received pre-exposure to the M2R selective antagonist AFDX-116 exhibited significantly reduced PS-PPR compared with slices that received DFP alone $[\mathrm{t}(17)=1.89, P=0.038$; Fig. 4G], whereas pretreatment of $\mathrm{vH}$ slices with AFDX-116 had no effect on PS-PPR following DFP wash-in [t(14) $=0.372$, $P=0.36$; Fig. $4 \mathrm{H}]$. Coexposure of $\mathrm{dH}[\mathrm{t}(12)=0.488, P=0.32]$ and $\mathrm{vH}[\mathrm{t}(13)=1.12, P=0.14]$ slices to ATR and MEC did not result in a significant reduction in the PS-PPR that was observed following DFP wash-in (Fig. 5, A and B, respectively). Together, these data suggest that cholinergic receptors do not mediate the PS-PPF that is observed following exposure of $\mathrm{dH}$ and $\mathrm{vH}$ slices to $30 \mu \mathrm{M}$ DFP.

NMDAR Blockade Prevents Population Spike Paired-Pulse Facilitation that Is Observed in Dorsal and Ventral Hippocampus Slices Exposed to DFP. Interestingly, PS-PPI was preserved in both $\mathrm{dH}[\mathrm{t}(14)=1.82$, $P=0.045]$ and vH $[\mathrm{t}(15)=2.24, P=0.020]$ slices treated with AFDX-116, MEC, and the NMDAR antagonist D-APV prior to DFP exposure (Fig. 5, C and D, respectively). PS-PPI persisted in $\mathrm{dH}[\mathrm{t}(14)=2.98, P=0.0049]$ and $\mathrm{vH}[\mathrm{t}(15)=2.21$, $P=0.021]$ slices pre-exposed to the three antagonists after 60 minutes DFP wash-out. No significant difference in PS-PPR was observed between $\mathrm{dH}$ and $\mathrm{vH}$ slices that received triple antagonist pretreatment. Additionally, 20 minutes of exposure to only D-APV resulted in a significant reduction in PS-PPR in $\mathrm{dH}[\mathrm{t}(8)=2.17, P=0.031]$ and $\mathrm{vH}[\mathrm{t}(5)=2.19$, $P=0.040]$ slices (Supplemental Fig. 2, C and D, respectively). D-APV pretreatment alone preserved PS-PPI in the $\mathrm{dH}$ [ $\mathrm{t}(15)$ $=3.24, P=0.0028]$ and the $\mathrm{vH}[\mathrm{t}(12)=2.28, P=0.021]$ following DFP wash-in (Fig. 5, E and F, respectively). When D-APV was the only antagonist present in the bath, PS-PPI persisted in the $\mathrm{dH}$ and $\mathrm{vH}$ following 60 minutes DFP washout $[\mathrm{t}(15)=3.59, P=0.0013 ; \mathrm{t}(12)=2.68, P=0.010$; respectively]. No significant difference in PS-PPR was observed between $\mathrm{dH}$ and $\mathrm{vH}$ slices pretreated with D-APV following DFP wash-in $[\mathrm{t}(13)=0.436, P=0.33]$ and 60 minutes DFP wash-out [t(13) $=0.720, P=0.24]$. Additionally, pretreatment with the RyR antagonist DAN resulted in a significant enhancement of PS-PPF observed in the $\mathrm{dH}$ [ $\mathrm{t}(14)$ $=3.22, P=0.0031]$ and the $\mathrm{vH}[\mathrm{t}(12)=2.42, P=0.016]$ following DFP exposure (Fig. 5, G and $\mathrm{H}$, respectively). Collectively, these data suggest that the NMDAR plays an indispensable role in mediating the PS-PPF that is observed in $\mathrm{dH}$ and $\mathrm{vH}$ slices exposed to $30 \mu \mathrm{M} \mathrm{DFP}$.

\section{Discussion}

The data in the present report demonstrate that DFPinduced PS1 inhibition in the $\mathrm{dH}$ and $\mathrm{vH}$ CA1 subfield is mediated by cholinergic receptors and NMDARs. Increased PS-PPR observed in $\mathrm{dH}$ and $\mathrm{vH}$ slices exposed to DFP is prevented by an NMDAR antagonist. To the best of our knowledge, this is the first report to comparatively characterize both cholinergic and noncholinergic effects of OP exposure on $\mathrm{dH}$ and $\mathrm{vH}$ synaptic transmission in a hippocampal slice preparation. Additionally, our findings of a DFP-NMDAR interaction affecting synaptic transmission are novel. Our results provide insight into the circuit-level role of the NMDAR in maintaining functional $\mathrm{RI}$ in the $\mathrm{dH}$ and the $\mathrm{vH}$ following exposure to an OP. The observed dorsoventralspecific effects may provide insight into OP-induced deficits in cognition and mood. A circuitry schematic containing the minimal components needed to explain the proposed dorsoventral-specific effects is presented in Fig. 6.

DFP has previously been employed to investigate the acute effects of an OP on the PS1, a response variable that can be directly correlated to the number of functional pyramidal cells in the stratum pyramidale of CA1 (Williamson and Sarvey, 1985; Jones et al., 1990; Ferchmin et al., 2015). Our results are consistent with these prior reports indicating that acute DFP exposure inhibits CA1 glutamatergic transmission and that a substantial component of this inhibition is mediated via cholinergic receptors. More specifically, following irreversible inhibition of AChE, enhanced synaptic ACh leads to hyperactivation of mAChRs, a well-established mechanism of OP-induced neurotoxicity (Abou-Donia et al., 2016). Previous studies have shown that mAChR blockade via ATR pretreatment partially prevents DFP-induced PS1 inhibition (Ferchmin et al., 2015). The present study showed that ATR pretreatment not only prevented DFP-mediated inhibition of the dH PS1 amplitude but also that the amplitude was in fact

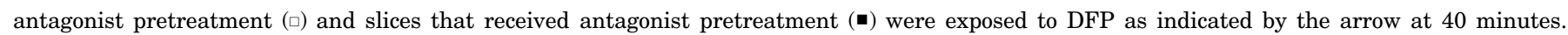

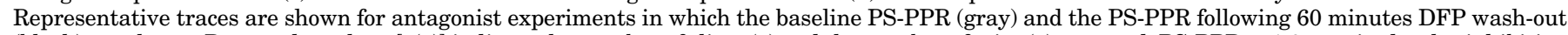

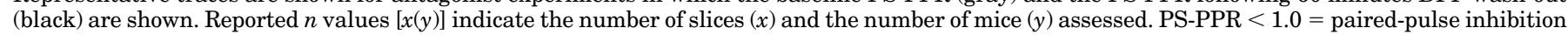
(PS-PPI); PS-PPR $>1.0=$ paired-pulse facilitation (PS-PPF). Data are expressed as mean \pm S.E.M. 
significantly enhanced by DFP application. Similarly, dH slices pretreated with AFDX-116 quantitatively resembled ATR experiments, suggesting that DFP-mediated PS1 inhibition is due to activation of M2Rs located in dH CA1. These receptors may be located at the Schaffer Collateral-CA1 synapse and somata of pyramidal cells (Vilaró et al., 1992; Auerbach and Segal, 1996; Seeger and Alzheimer, 2001; Seeger et al., 2004), where activation of these M2Rs enhances $\mathrm{K}^{+}$conductance, hyperpolarizing principal cells and decreasing excitatory glutamatergic transmission (Drever et al., 2011). In support of these findings, prior evidence indicates OPs preferentially act as indirect agonists via M2Rs (Liu et al., 2002).

ACh-mediated activation of nAChRs on pyramidal cells enhances cation conduction, facilitating principal cell depolarization (Albuquerque et al., 2009). Interestingly, nAChR blockade enhanced DFP-mediated PS1 inhibition in both the $\mathrm{dH}$ and the $\mathrm{vH}$. Prior evidence indicates that acute OP exposure accelerates the rate of $\mathrm{nAChR}$ desensitization (Tattersall, 1990), an effect that may contribute to the enhanced PS1 inhibition observed in the present study. Specifically, this enhanced inhibition may be a result of reducing the excitatory tone of $\alpha 7$-like nAChRs located on stratum pyramidale principal cells (Castro and Albuquerque, 1993; Mike et al., 2000). Additionally, reducing the activity of CA1 interneuron-selective interneurons following the blockade of $\alpha 4 \beta 2$-like nAChRs would also decrease pyramidal cell excitability, reducing the PS1 amplitude (Bell et al., 2015).

Direct interactions of OPs with cholinergic receptors are well established (Pope, 1999; Pope et al., 2005). A number of reports have indicated that OPs and other AChE inhibitors directly compete at the agonist site of M2Rs (Bakry et al., 1988; Silveira et al., 1990; Fitzgerald and Costa, 1992; Ward et al., 1993; Ward and Mundy, 1996; Rocha et al., 1999; Santos et al., 2003) or directly phosphorylate (Bomser and Casida, 2001) M2Rs. Moreover, OPs have been shown to preferentially interact with M2/M4 mAChRs and activate their G $\alpha /$ i-coupled pathways (Ward et al., 1993; Ward and Mundy, 1996). We postulate that AChE-independent mechanisms may underlie some of the results observed in the present study. In particular, no increase in AChE inhibition was observed at DFP concentrations greater than $10 \mu \mathrm{M}$, yet progressively greater inhibition of the PS1 was observed at higher concentrations. Furthermore, we observed a noteworthy recovery of the PS1 amplitude in dose-response experiments utilizing $100 \mu \mathrm{M}$ DFP. We attribute this recovery to wash-out of DFP following direct interaction with nAChRs on pyramidal cells. This interpretation is supported by previous reports of DFP directly inducing $\mathrm{nAChR}$ desensitization at concentrations near $100 \mu \mathrm{M}$ (Albuquerque et al., 1984; Bakry et al., 1988; Eldefrawi et al., 1988).

A number of noncholinergic mechanisms mediating OP effects have been characterized. DFP and other OPs covalently interact with lysine and tyrosine residues of structural proteins such as tubulin, actin, and kinesin, resulting in axonal transport deficits (Grigoryan et al., 2008, 2009; Jiang et al., 2010). A recent report demonstrated that subacute DFP exposure leads to structural disruptions of myelinated axons, a putative result of axonal transport deficits (Naughton et al., 2018). AChE-independent decreases in mitochondrial number and energetics following OP exposure have been described

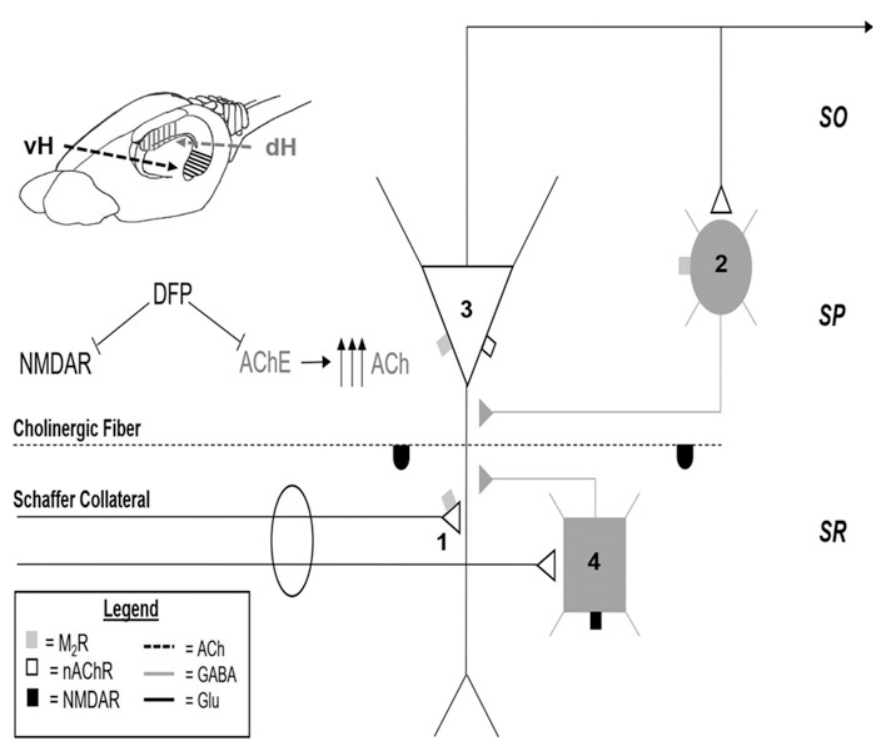

Fig. 6. Proposed schematic illustrating the effects of DFP on dorsal $(\mathrm{dH})$ and ventral $(\mathrm{vH})$ hippocampal neurocircuitry in relation to the mAChR, the nAChR, and the NMDAR. DFP induces irreversible AChE inhibition, leading to M2R-mediated PS1 inhibition in the $\mathrm{dH}$ (1,3; gray). DFP induces PS1 inhibition through an M2R, nAChR, and NMDAR-dependent mechanism in the $\mathrm{vH}(1,3,4$; black). Following DFP exposure, PS-PPI shifts to PS-PPF in the $\mathrm{dH}$ and the vH. PS-PPI can be partially preserved by M2R blockade in the $\mathrm{dH}$ (2) or completely preserved by NMDAR blockade in the $\mathrm{dH}$ or the $\mathrm{vH}$ (4). SO, stratum oriens; SP, stratum pyramidale; SR, stratum radiatum.

(Kaur et al., 2007; Middlemore-Risher et al., 2010). Moreover, a series of reports have emphasized the role of the NMDAR in initiating $\mathrm{Ca}^{2+}$-induced $\mathrm{Ca}^{2+}$ release mechanisms after OP exposure (Deshpande et al., 2010; Phillips et al., 2019). Interestingly, DFP has been shown to directly interact with the glutamate-binding pocket of the NMDAR, irreversibly inhibiting the receptor (Johnson and Michaelis, 1992). In the present report, we observed a partial reduction of DFPmediated pyramidal cell inhibition in $\mathrm{dH}$ and $\mathrm{vH}$ slices pretreated with an NMDAR competitive antagonist. Experiments in which slices were pre-exposed to AFDX-116, D-APV, and MEC completely prevented DFP-mediated pyramidal cell inhibition. There is evidence that bath application of an NMDAR antagonist disinhibits glutamatergic transmission (Čapek and Esplin, 1991; Grunze et al., 1996), which may contribute to preventing the DFP-mediated PS1 inhibition. Blockade of RyRs, receptors involved in $\mathrm{Ca}^{2+}$-induced $\mathrm{Ca}^{2+}$ release, enhanced DFP-mediated PS1 inhibition in the $\mathrm{dH}$ and the $\mathrm{vH}$, an effect that may involve decreased pyramidal cell excitability because of disruption of $\left[\mathrm{Ca}^{2+}\right] \mathrm{i}$ homeostasis. There is also evidence suggesting OPs directly interact with receptors involved in $\mathrm{Ca}^{2+}$-induced $\mathrm{Ca}^{2+}$ release (Sun et al., 2000), an interaction that may further contribute to the disruption of $\left[\mathrm{Ca}^{2+}\right]$ i homeostasis. Noncholinergic mechanisms unexplored in the present study, such as endocannabinoid signaling, promote OP-induced modulations in the hippocampus (Nallapaneni et al., 2006, 2008; Wright et al., 2010; Hoffman et al., 2019). Future studies investigating such noncholinergic mechanisms may be fruitful, particularly because there is a paucity of reports characterizing the effects of OPs on cannabinoid signaling along the hippocampal dorsoventral axis.

Recurrent inhibition modulates principal cell excitability and network functionality by ensuring a sufficient GABAergic 
inhibitory tone is present in the CA1 subfield (Andersen et al., 1963; Papatheodoropoulos and Kostopoulos, 1998). When using the double orthodromic stimulation protocol to monitor RI in the CA1 subfield of healthy hippocampal tissue (Michelson and Lothman, 1989; Sloviter, 1991), a paired-pulse interpulse interval of $10 \mathrm{~ms}$ results in fast-acting, ionotropic $\mathrm{GABA}_{\mathrm{A}}$ receptor-mediated PS PS-PPI (PS2/PS1 <1) (Papatheodoropoulos et al., 2002; Petrides et al., 2007). It has been noted that a linear increase in PPR is observed as $\mathrm{GABA}_{\mathrm{A}}$ receptor-mediated inhibition decreases (Lopes da Silva et al., 1995). Therefore, we monitored the PS-PPR as a measurement of functional synaptic inhibition in CA1, where it would be expected that a decrease in RI would result in an increase in PS-PPR. This was observed in $\mathrm{dH}$ and $\mathrm{vH}$ slices treated with $30 \mu \mathrm{M}$ DFP, in which an initial PS-PPI response was shifted to PS-PPF. Interestingly, individual or coapplication of $\mathrm{mAChR}$ and nAChR antagonists had no significant effect on the PSPPF that was observed following DFP application. Nonetheless, we observed a marginal preservation of PS-PPI when slices were pretreated with AFDX-116. A previous report demonstrated that activation of mAChRs reduced the frequency of tetrodotoxin-insensitive miniature inhibitory postsynaptic currents as well as monosynaptically evoked inhibitory postsynaptic currents, resulting in weakened RI (Behrends and ten Bruggencate, 1993). M2Rs are frequently expressed on parvalbumin-positive interneurons, and blocking these receptors increases GABA release from perisomatic parvalbumin-positive cells (Hájos et al., 1998; Fukudome et al., 2004; Szabó et al., 2010) as illustrated in Fig. 6, a result consistent with our AFDX-116 experiments.

Strikingly, NMDAR antagonist pretreatment alone or combined with cholinergic antagonists preserved PS-PPI following DFP treatment. Previous reports have shown that GABAergic input onto CA1 principal neurons is modulated by NMDAR-dependent transmission, where bath application of D-APV reduces CA1 pyramidal cell RI postsynaptic potential by more than $30 \%$ (Grunze et al., 1996). The unique subunit composition and receptor density of NMDAR-expressing interneurons facilitate enhanced sensitivity to D-APV compared with NMDAR-expressing principal cells (Monyer et al., 1994; Martina et al., 2003, 2013; Nyiri et al., 2003; Avignone et al., 2005). Therefore, we postulate that the preservation of PS-PPI in D-APV pretreatment experiments is a result of the modulatory role of NMDAR-expressing interneurons. Specifically, blockade of the NMDAR results in disinhibition of pyramidal cells, thereby promoting excitation of perisomatic interneurons mediating RI and preserving PS-PPI. We also observed a significant reduction of $\mathrm{dH}$ and $\mathrm{vH}$ PS-PPR during D-APV application, which is consistent with our NMDARmediated disinhibition hypothesis. As this is the first report of the NMDAR modulating the PS-PPR in the presence of an $\mathrm{AChE}$ inhibitor, further investigation into this mechanism is warranted.

The long-range in vivo projections comprising the septohippocampal system are complex (Teles-Grilo Ruivo and Mellor, 2013), making the hippocampal slice preparation a sufficient but limited model for investigating cholinergic and noncholinergic mechanisms that mediate the effects of OPs on synaptic transmission along the hippocampal dorsoventral axis. At the behavioral level, the $\mathrm{dH}$ is associated with spatial memory, whereas the $\mathrm{vH}$ facilitates emotional-related responses (Floresco et al., 1997; Moser and Moser, 1998; Bannerman et al., 2004;
Pothuizen et al., 2004; Tamura et al., 2017). Receptor densities differ between the $\mathrm{dH}$ and $\mathrm{vH}$ sectors, resulting in intrinsic synaptic distinctions (Pandis et al., 2006; Petrides et al., 2007; Segal et al., 2010; Papatheodoropoulos, 2018). In the context of hippocampal cholinergic transmission, differential cholinergic projection (Milner et al., 1983; Amaral and Kurz, 1985) and receptor densities (Garcia Ruiz et al., 1993; Jung et al., 1994; Huang and Winzer-Serhan, 2006; Kenney et al., 2012) are found along the hippocampal dorsoventral axis. In light of these previous reports, accounting for dorsoventral-specific effects of OP exposure may be critical in interpreting the impact of exposure to these agents. For instance, we observed a reduction of DFP-mediated pyramidal cell inhibition in $\mathrm{dH}$ and $\mathrm{vH}$ slices pretreated with an NMDAR antagonist, an effect that was statistically significant in the $\mathrm{dH}$ but not in the $\mathrm{vH}$. These statistical differences may be attributed to significantly greater expression of GluN2A and GluN2B subunits in the $\mathrm{dH}$ CA1 compared with the vH CA1 (Pandis et al., 2006). This may be particularly relevant to OP exposure in a low-level exposure setting such as the 1990-1991 Gulf War, in which OP nerve agent exposure has been associated with a dosedependent impairment of cognition and structural hippocampal abnormalities (Heaton et al., 2007; Chao et al., 2017). Additionally, cognitive impairments following low-level exposure to OP pesticides in agricultural settings have been reported (Rohlman et al., 2011). Given the present evidence for NMDAR involvement of DFP-mediated effects on synaptic transmission, our findings underscore the value of future investigations of therapeutic agents that target noncholinergic mechanisms in cases of low-level OP exposures that lead to persisting cognitive impairments.

\section{Acknowledgments}

We thank Caroline Grant for the anatomical illustration of the hippocampus in Fig. 6.

\section{Authorship Contributions}

Participated in research design: Brown, Filipov, Wagner.

Conducted experiments: Brown.

Contributed reagents or analytic tools: Filipov, Wagner.

Performed data analysis: Brown.

Wrote or contributed to the writing of the manuscript: Brown, Filipov, Wagner.

\section{References}

Abou-Donia MB (2003) Organophosphorus ester-induced chronic neurotoxicity. Arch Environ Health 58:484-497.

Abou-Donia MB, Siracuse B, Gupta N, and Sobel Sokol A (2016) Sarin (GB, O-isopropyl methylphosphonofluoridate) neurotoxicity: critical review. Crit Rev Toxicol 46:845-875.

Albuquerque EX, Akaike A, Shaw K-P, and Rickett DL (1984) The interaction of anticholinesterase agents with the acetylcholine receptor-ionic channel complex. Fundam Appl Toxicol 4:S27-S33.

Albuquerque EX, Pereira EF, Alkondon M, and Rogers SW (2009) Mammalian nicotinic acetylcholine receptors: from structure to function. Physiol Rev 89:73-120.

Amaral DG and Kurz J (1985) An analysis of the origins of the cholinergic and noncholinergic septal projections to the hippocampal formation of the rat. J Comp Neurol 240:37-59.

Andersen P, Eccles JC, and Løyning Y (1963) Recurrent inhibition in the hippocampus with identification of the inhibitory cell and its synapses. Nature 198: 540-542.

Apland JP, Figueiredo TH, Qashu F, Aroniadou-Anderjaska V, Souza AP, and Braga MF (2010) Higher susceptibility of the ventral versus the dorsal hippocampus and the posteroventral versus anterodorsal amygdala to soman-induced neuropathology. Neurotoxicology 31:485-492.

Auerbach JM and Segal M (1996) Muscarinic receptors mediating depression and long-term potentiation in rat hippocampus. J Physiol 492:479-493.

Avignone E, Frenguelli BG, and Irving AJ (2005) Differential responses to NMDA receptor activation in rat hippocampal interneurons and pyramidal cells may underlie enhanced pyramidal cell vulnerability. Eur J Neurosci 22:3077-3090. 
Bakry NM, el-Rashidy AH, Eldefrawi AT, and Eldefrawi ME (1988) Direct actions of organophosphate anticholinesterases on nicotinic and muscarinic acetylcholine receptors. J Biochem Toxicol 3:235-259.

Banks CN and Lein PJ (2012) A review of experimental evidence linking neurotoxic organophosphorus compounds and inflammation. Neurotoxicology 33:575-584.

Bannerman DM, Rawlins JN, McHugh SB, Deacon RM, Yee BK, Bast T, Zhang W-N Pothuizen HH, and Feldon J (2004) Regional dissociations within the hippocampus--memory and anxiety. Neurosci Biobehav Rev 28:273-283.

Behrends JC and ten Bruggencate G (1993) Cholinergic modulation of synaptic inhibition in the guinea pig hippocampus in vitro: excitation of GABAergic interneurons and inhibition of GABA-release. J Neurophysiol 69:626-629.

Bell LA, Bell KA, and McQuiston AR (2015) Acetylcholine release in mouse hippocampal CA1 preferentially activates inhibitory-selective interneurons via $\alpha 4 \beta 2 *$ nicotinic receptor activation. Front Cell Neurosci 9:115.

Benardo LS and Prince DA (1982a) Cholinergic excitation of mammalian hippocampal pyramidal cells. Brain Res 249:315-331.

Benardo LS and Prince DA (1982b) Ionic mechanisms of cholinergic excitation in mammalian hippocampal pyramidal cells. Brain Res 249:333-344

Bomser JA and Casida JE (2001) Diethylphosphorylation of rat cardiac M2 muscarinic receptor by chlorpyrifos oxon in vitro. Toxicol Lett 119:21-26.

Bradford MM (1976) A rapid and sensitive method for the quantitation of microgram quantities of protein utilizing the principle of protein-dye binding. Anal Biochem 72:248-254.

Capek R and Esplin B (1991) Attenuation of hippocampal inhibition by a NMDA (N-methyl-D-aspartate) receptor antagonist. Neurosci Lett 129:145-148.

Casida JE and Quistad GB (2004) Organophosphate toxicology: safety aspects of nonacetylcholinesterase secondary targets. Chem Res Toxicol 17:983-998.

Castro NG and Albuquerque EX (1993) Brief-lifetime, fast-inactivating ion channels account for the $\alpha$-bungarotoxin-sensitive nicotinic response in hippocampal neurons. Neurosci Lett 164:137-140.

Chambers J, Wiygul S, Harkness J, and Chambers H (1988) Effects of acute paraoxon and atropine exposures on retention of shuttle avoidance-behavior in rats. Neurosci Res Commun 3:85-92.

Chambers JE and Chambers HW (1989) Short-term effects of paraoxon and atropine on schedule-controlled behavior in rats. Neurotoxicol Teratol 11:427-432.

Chao LL, Raymond MR, Leo CK, and Abadjian LR (2017) Evidence of hippocampal structural alterations in Gulf war veterans with predicted exposure to the khamisiyah plume. J Occup Environ Med 59:923-929.

Deshpande LS, Carter DS, Blair RE, and DeLorenzo RJ (2010) Development of a prolonged calcium plateau in hippocampal neurons in rats surviving status epilepticus induced by the organophosphate diisopropylfluorophosphate. Toxicol Sci 116:623-631.

Drever BD, Riedel G, and Platt B (2011) The cholinergic system and hippocampal plasticity. Behav Brain Res 221:505-514.

Eaton DL, Daroff RB, Autrup H, Bridges J, Buffler P, Costa LG, Coyle J, McKhann G, Mobley WC, Nadel L, et al. (2008) Review of the toxicology of chlorpyrifos with an emphasis on human exposure and neurodevelopment. Crit Rev Toxicol 38 (Suppl 2):1-125.

Eldefrawi ME, Schweizer G, Bakry NM, and Valdes JJ (1988) Desensitization of the nicotinic acetylcholine receptor by diisopropylfluorophosphate. J Biochem Toxicol 3:21-32.

Ellman GL, Courtney KD, Andres V Jr, and Feather-Stone RM (1961) A new and rapid colorimetric determination of acetylcholinesterase activity. Biochem Pharmacol 7:88-95.

Fanselow MS and Dong H-W (2010) Are the dorsal and ventral hippocampus functionally distinct structures? Neuron 65:7-19.

Ferchmin PA, Pérez D, Cuadrado BL, Carrasco M, Martins AH, and Eterović VA (2015) Neuroprotection against diisopropylfluorophosphate in acute hippocampal slices. Neurochem Res 40:2143-2151.

Fitzgerald BB and Costa LG (1992) Modulation of M1 and M2 muscarinic receptor subtypes following repeated organophosphate exposure in rats. Toxicol Appl Pharmacol 117:122-125.

Floresco SB, Seamans JK, and Phillips AG (1997) Selective roles for hippocampal, prefrontal cortical, and ventral striatal circuits in radial-arm maze tasks with or without a delay. J Neurosci 17:1880-1890.

Fukudome Y, Ohno-Shosaku T, Matsui M, Omori Y, Fukaya M, Tsubokawa H, Taketo MM, Watanabe M, Manabe T, and Kano M (2004) Two distinct classes of muscarinic action on hippocampal inhibitory synapses: M2-mediated direct suppression and M1/M3-mediated indirect suppression through endocannabinoid signalling. Eur J Neurosci 19:2682-2692.

Garcia Ruiz AJ, Zambelli M, La Porta C, Ladinsky H, and Consolo S (1993) Differences between rat dorsal and ventral hippocampus in muscarinic receptor agonist binding and interaction with phospholipase C. Eur J Pharmacol 244:125-131.

Grigoryan H, Li B, Anderson EK, Xue W, Nachon F, Lockridge O, and Schopfer LM (2009) Covalent binding of the organophosphorus agent FP-biotin to tyrosine in eight proteins that have no active site serine. Chem Biol Interact 180:492-498.

Grigoryan H, Schopfer LM, Thompson CM, Terry AV, Masson P, and Lockridge O (2008) Mass spectrometry identifies covalent binding of soman, sarin, chlorpyrifos oxon, diisopropyl fluorophosphate, and FP-biotin to tyrosines on tubulin a potential mechanism of long term toxicity by organophosphorus agents. Chem Biol Interact 175:180-186.

Grunze HC, Rainnie DG, Hasselmo ME, Barkai E, Hearn EF, McCarley RW, and Greene RW (1996) NMDA-dependent modulation of CA1 local circuit inhibition. J Neurosci 16:2034-2043.

Hájos N, Papp EC, Acsády L, Levey AI, and Freund TF (1998) Distinct interneuron types express $\mathrm{m} 2$ muscarinic receptor immunoreactivity on their dendrites or axon terminals in the hippocampus. Neuroscience 82:355-376.

Hasselmo ME (2006) The role of acetylcholine in learning and memory. Curr Opin Neurobiol 16:710-715.

Heaton KJ, Palumbo CL, Proctor SP, Killiany RJ, Yurgelun-Todd DA, and White RF (2007) Quantitative magnetic resonance brain imaging in US army veterans of the
1991 Gulf War potentially exposed to sarin and cyclosarin. Neurotoxicology 28: 761-769.

Hoffman KM, Eisen MR, Chandler JK, Nelson MR, Johnson EA, and McNutt PM (2019) Retrograde activation of CB1R by muscarinic receptors protects against central organophosphorus toxicity. Neuropharmacology 155:113-120.

Hood E (2001) The Tokyo attacks in retrospect: sarin leads to memory loss. Environ Health Perspect 109:A542.

Huang LZ and Winzer-Serhan UH (2006) Chronic neonatal nicotine upregulates heteromeric nicotinic acetylcholine receptor binding without change in subunit mRNA expression. Brain Res 1113:94-109.

Jiang W, Duysen EG, Hansen H, Shlyakhtenko L, Schopfer LM, and Lockridge O (2010) Mice treated with chlorpyrifos or chlorpyrifos oxon have organophosphorylated tubulin in the brain and disrupted microtubule structures, suggesting a role for tubulin in neurotoxicity associated with exposure to organophosphorus agents. Toxicol Sci 115:183-193.

Johnson PS and Michaelis EK (1992) Characterization of organophosphate interactions at $\mathrm{N}$-methyl-D-aspartate receptors in brain synaptic membranes. Mol Pharmacol 41:750-756

Jones LS, Lapadula DM, Lewis DV, and Abou-Donia MB (1990) Effects of diisopropyl phosphorofluoridate (DFP) on CA3 and CA1 responses in rat hippocampus. Mol Chem Neuropathol 13:1-16.

Jung MW, Wiener SI, and McNaughton BL (1994) Comparison of spatial firing characteristics of units in dorsal and ventral hippocampus of the rat. J Neurosci 14 7347-7356.

Kaplan JG, Kessler J, Rosenberg N, Pack D, and Schaumburg HH (1993) Sensory neuropathy associated with Dursban (chlorpyrifos) exposure. Neurology 43: 2193-2196

Kaur P, Radotra B, Minz RW, and Gill KD (2007) Impaired mitochondrial energy metabolism and neuronal apoptotic cell death after chronic dichlorvos (OP) exposure in rat brain. Neurotoxicology 28:1208-1219.

Kenney JW, Raybuck JD, and Gould TJ (2012) Nicotinic receptors in the dorsal and ventral hippocampus differentially modulate contextual fear conditioning. Hippocampus 22:1681-1690.

Keralapurath MM, Briggs SB, and Wagner JJ (2017) Cocaine self-administration induces changes in synaptic transmission and plasticity in ventral hippocampus. Addict Biol 22:446-456.

Liu J, Chakraborti T, and Pope C (2002) In vitro effects of organophosphorus anticholinesterases on muscarinic receptor-mediated inhibition of acetylcholine release in rat striatum. Toxicol Appl Pharmacol 178:102-108.

Locker AR, Michalovicz LT, Kelly KA, Miller JV, Miller DB, and O'Callaghan JP (2017) Corticosterone primes the neuroinflammatory response to Gulf War Illnessrelevant organophosphates independently of acetylcholinesterase inhibition. $J$ Neurochem 142:444-455.

Lopes da Silva FH, Kamphuis W, Titulaer M, Vreugdenhil M, and Wadman WJ (1995) An experimental model of progressive epilepsy: the development of kindling of the hippocampus of the rat. Ital J Neurol Sci 16:45-57.

Madison DV, Lancaster B, and Nicoll RA (1987) Voltage clamp analysis of cholinergic action in the hippocampus. $J$ Neurosci 7:733-741.

Martina M, Comas T, and Mealing GA (2013) Selective pharmacological modulation of pyramidal neurons and interneurons in the CA1 region of the rat hippocampus. Front Pharmacol 4:24.

Martina M, Krasteniakov NV, and Bergeron R (2003) D-Serine differently modulates NMDA receptor function in rat CA1 hippocampal pyramidal cells and interneurons. J Physiol 548:411-423.

Mense SM, Sengupta A, Lan C, Zhou M, Bentsman G, Volsky DJ, Whyatt RM, Perera FP, and Zhang L (2006) The common insecticides cyfluthrin and chlorpyrifos alter the expression of a subset of genes with diverse functions in primary human astrocytes. Toxicol Sci 93:125-135.

Michaelis S, Burdon J, and Howard CV; World Health Organization. Regional Office for Europe (2017) Aerotoxic syndrome: a new occupational disease? Public Health Panor 3:198-211.

Michalovicz LT, Locker AR, Kelly KA, Miller JV, Barnes Z, Fletcher MA, Miller DB, Klimas NG, Morris M, Lasley SM, et al. (2019) Corticosterone and pyridostigmine/ DEET exposure attenuate peripheral cytokine expression: supporting a dominant role for neuroinflammation in a mouse model of Gulf War Illness. Neurotoxicology 70:26-32.

Michelson HB and Lothman EW (1989) An in vivo electrophysiological study of the ontogeny of excitatory and inhibitory processes in the rat hippocampus. Brain Res Dev Brain Res 47:113-122.

Middlemore-Risher M-L, Buccafusco JJ, and Terry AV Jr (2010) Repeated exposure to low-level chlorpyrifos results in impairments in sustained attention and increased impulsivity in rats. Neurotoxicol Teratol 32:415-424.

Mike A, Castro NG, and Albuquerque EX (2000) Choline and acetylcholine have similar kinetic properties of activation and desensitization on the $\alpha 7$ nicotinic receptors in rat hippocampal neurons. Brain Res 882:155-168.

Miller JV, LeBouf RF, Kelly KA, Michalovicz LT, Ranpara A, Locker AR, Miller DB, and O'Callaghan JP (2018) The neuroinflammatory phenotype in a mouse model of Gulf War Illness is unrelated to brain regional levels of acetylcholine as measured by quantitative HILIC-UPLC-MS/MS. Toxicol Sci 165:302-313.

Milner TA, Loy R, and Amaral DG (1983) An anatomical study of the development of the septo-hippocampal projection in the rat. Brain Res 284:343-371.

Miyaki K, Nishiwaki Y, Maekawa K, Ogawa Y, Asukai N, Yoshimura K, Etoh N, Matsumoto Y, Kikuchi Y, Kumagai N, et al. (2005) Effects of sarin on the nervous system of subway workers seven years after the Tokyo subway sarin attack. J Occup Health 47:299-304.

Monyer H, Burnashev N, Laurie DJ, Sakmann B, and Seeburg PH (1994) Developmental and regional expression in the rat brain and functional properties of four NMDA receptors. Neuron 12:529-540.

Moser MB and Moser EI (1998) Functional differentiation in the hippocampus. Hippocampus 8:608-619. 
Nallapaneni A, Liu J, Karanth S, and Pope C (2006) Modulation of paraoxon toxicity by the cannabinoid receptor agonist WIN 55,212-2. Toxicology 227:173-183.

Nallapaneni A, Liu J, Karanth S, and Pope C (2008) Pharmacological enhancement of endocannabinoid signaling reduces the cholinergic toxicity of diisopropylfluorophosphate. Neurotoxicology 29:1037-1043.

Naughton SX, Hernandez CM, Beck WD, Poddar I, Yanasak N, Lin P-C, and Terry AV Jr (2018) Repeated exposures to diisopropylfluorophosphate result in structural disruptions of myelinated axons and persistent impairments of axonal transport in the brains of rats. Toxicology 406-407:92-103.

Naughton SX and Terry AV Jr (2018) Neurotoxicity in acute and repeated organophosphate exposure. Toxicology 408:101-112.

Nishiwaki Y, Maekawa K, Ogawa Y, Asukai N, Minami M, and Omae K; Sarin Health Effects Study Group (2001) Effects of sarin on the nervous system in rescue team staff members and police officers 3 years after the Tokyo subway sarin attack. Environ Health Perspect 109:1169-1173.

Nyíri G, Stephenson FA, Freund TF, and Somogyi P (2003) Large variability in synaptic N-methyl-D-aspartate receptor density on interneurons and a comparison with pyramidal-cell spines in the rat hippocampus. Neuroscience 119:347-363.

O'Callaghan JP, Kelly KA, Locker AR, Miller DB, and Lasley SM (2015) Corticosterone primes the neuroinflammatory response to DFP in mice: potential animal model of Gulf War Illness. J Neurochem 133:708-721.

Pandis C, Sotiriou E, Kouvaras E, Asprodini E, Papatheodoropoulos C, and Angelatou F (2006) Differential expression of NMDA and AMPA receptor subunits in rat dorsal and ventral hippocampus. Neuroscience 140:163-175.

Papatheodoropoulos C (2018) Electrophysiological evidence for long-axis intrinsic diversification of the hippocampus. Front Biosci 23:109-145.

Papatheodoropoulos C, Asprodini E, Nikita I, Koutsona C, and Kostopoulos G (2002) Weaker synaptic inhibition in CA1 region of ventral compared to dorsal rat hippocampal slices. Brain Res 948:117-121.

Papatheodoropoulos C and Kostopoulos G (1998) Development of a transient increase in recurrent inhibition and paired-pulse facilitation in hippocampal CA1 region. Brain Res Dev Brain Res 108:273-285.

Petrides T, Georgopoulos P, Kostopoulos G, and Papatheodoropoulos C (2007) The GABAA receptor-mediated recurrent inhibition in ventral compared with dorsal CA1 hippocampal region is weaker, decays faster and lasts less. Exp Brain Res 177:370-383.

Phillips KF, Santos E, Blair RE, and Deshpande LS (2019) Targeting intracellular calcium stores alleviates neurological morbidities in a DFP-based rat model of Gulf War Illness. Toxicol Sci 169:567-578.

Pope C, Karanth S, and Liu J (2005) Pharmacology and toxicology of cholinesterase inhibitors: uses and misuses of a common mechanism of action. Environ Toxicol Pharmacol 19:433-446.

Pope CN (1999) Organophosphorus pesticides: do they all have the same mechanism of toxicity? J Toxicol Environ Health B Crit Rev 2:161-181.

Pothuizen HH, Zhang WN, Jongen-Rêlo AL, Feldon J, and Yee BK (2004) Dissociation of function between the dorsal and the ventral hippocampus in spatial learning abilities of the rat: a within-subject, within-task comparison of reference and working spatial memory. Eur J Neurosci 19:705-712.

Pouliot W, Bealer SL, Roach B, and Dudek FE (2016) A rodent model of human organophosphate exposure producing status epilepticus and neuropathology. Neurotoxicology 56:196-203.

Prendergast MA, Terry AV Jr, and Buccafusco JJ (1997) Chronic, low-level exposure to diisopropylfluorophosphate causes protracted impairment of spatial navigation learning. Psychopharmacology (Berl) 129:183-191.

Prendergast MA, Terry AV Jr, and Buccafusco JJ (1998) Effects of chronic, low-level organophosphate exposure on delayed recall, discrimination, and spatial learning in monkeys and rats. Neurotoxicol Teratol 20:115-122.

Preston CJ, Brown KA, and Wagner JJ (2019) Cocaine conditioning induces persisting changes in ventral hippocampus synaptic transmission, long-term potentiation, and radial arm maze performance in the mouse. Neuropharmacology 150: 27-37.

Proctor SP, Heaton KJ, Heeren T, and White RF (2006) Effects of sarin and cyclosarin exposure during the 1991 Gulf War on neurobehavioral functioning in US army veterans. Neurotoxicology 27:931-939.

Rocha ES, Santos MD, Chebabo SR, Aracava Y, and Albuquerque EX (1999) Low concentrations of the organophosphate VX affect spontaneous and evoked transmitter release from hippocampal neurons: toxicological relevance of cholinesteraseindependent actions. Toxicol Appl Pharmacol 159:31-40.

Rohlman DS, Anger WK, and Lein PJ (2011) Correlating neurobehavioral performance with biomarkers of organophosphorous pesticide exposure. Neurotoxicology 32:268-276.

Ross SM, McManus IC, Harrison V, and Mason O (2013) Neurobehavioral problems following low-level exposure to organophosphate pesticides: a systematic and metaanalytic review. Crit Rev Toxicol 43:21-44.

Santos MD, Pereira EF, Aracava Y, Castro NG, Fawcett WP, Randall WR, and Albuquerque EX (2003) Low concentrations of pyridostigmine prevent somaninduced inhibition of GABAergic transmission in the central nervous system: involvement of muscarinic receptors. J Pharmacol Exp Ther 304:254-265.
Saunders BC (1957) Some Aspects of the Chemistry and Toxic Action of Organic Compounds Containing Phosphorus and Fluorine p 42, Cambridge University Press, London, United Kingdom.

Seeger T and Alzheimer C (2001) Muscarinic activation of inwardly rectifying $\mathrm{K}(+)$ conductance reduces EPSPs in rat hippocampal CA1 pyramidal cells. J Physiol 535:383-396.

Seeger T, Fedorova I, Zheng F, Miyakawa T, Koustova E, Gomeza J, Basile AS, Alzheimer C, and Wess J (2004) M2 muscarinic acetylcholine receptor knock-out mice show deficits in behavioral flexibility, working memory, and hippocampal plasticity. J Neurosci 24:10117-10127.

Segal M, Richter-Levin G, and Maggio N (2010) Stress-induced dynamic routing of hippocampal connectivity: a hypothesis. Hippocampus 20:1332-1338.

Silveira CL, Eldefrawi AT, and Eldefrawi ME (1990) Putative M2 muscarinic receptors of rat heart have high affinity for organophosphorus anticholinesterases. Toxicol Appl Pharmacol 103:474-481.

Sloviter RS (1991) Feedforward and feedback inhibition of hippocampal principal cell activity evoked by perforant path stimulation: GABA-mediated mechanisms that regulate excitability in vivo. Hippocampus 1:31-40.

Stewart M and Fox SE (1990) Do septal neurons pace the hippocampal theta rhythm? Trends Neurosci 13:163-168.

Sun X, Liu X-B, Martinez JR, and Zhang GH (2000) Effects of low concentrations of paraoxon on $\mathrm{Ca}(2+)$ mobilization in a human parotid salivary cell-line HSY. Arch Oral Biol 45:621-638.

Szabó GG, Holderith N, Gulyás AI, Freund TF, and Hájos N (2010) Distinct synaptic properties of perisomatic inhibitory cell types and their different modulation by cholinergic receptor activation in the CA3 region of the mouse hippocampus. Eur J Neurosci 31:2234-2246.

Talabani JM, Ali AI, Kadir AM, Rashid R, Samin F, Greenwood D, and Hay A (2018) Long-term health effects of chemical warfare agents on children following a single heavy exposure. Hum Exp Toxicol 37:836-847.

Tamura M, Spellman TJ, Rosen AM, Gogos JA, and Gordon JA (2017) Hippocampalprefrontal theta-gamma coupling during performance of a spatial working memory task. Nat Commun 8:2182.

Tattersall JE (1990) Effects of organophosphorus anticholinesterases on nicotinic receptor ion channels at adult mouse muscle endplates. $\mathrm{Br} J$ Pharmacol 101: 349-357.

Teles-Grilo Ruivo LM and Mellor JR (2013) Cholinergic modulation of hippocampal network function. Front Synaptic Neurosci 5:2.

Terry AV Jr, Beck WD, Warner S, Vandenhuerk L, and Callahan PM (2012) Chronic impairments in spatial learning and memory in rats previously exposed to chlorpyrfos or diisopropylfluorophosphate. Neurotoxicol Teratol 34:1-8.

Terry AV Jr, Buccafusco JJ, Gearhart DA, Beck WD, Middlemore-Risher M-L, Truan JN, Schwarz GM, Xu M, Bartlett MG, Kutiyanawala A, et al. (2011) Repeated, intermittent exposures to diisopropylfluorophosphate in rats: protracted effects on cholinergic markers, nerve growth factor-related proteins, and cognitive function. Neuroscience 176:237-253.

Todorovic MS, Cowan ML, Balint CA, Sun C, and Kapur J (2012) Characterization of status epilepticus induced by two organophosphates in rats. Epilepsy Res 101: 268-276.

Vertes RP and Kocsis B (1997) Brainstem-diencephalo-septohippocampal systems controlling the theta rhythm of the hippocampus. Neuroscience 81:893-926.

Vilaró MT, Wiederhold KH, Palacios JM, and Mengod G (1992) Muscarinic M2selective ligands also recognize M4 receptors in the rat brain: evidence from combined in situ hybridization and receptor autoradiography. Synapse 11: 171-183.

Ward TR, Ferris DJ, Tilson HA, and Mundy WR (1993) Correlation of the anticholinesterase activity of a series of organophosphates with their ability to compete with agonist binding to muscarinic receptors. Toxicol Appl Pharmacol 122: 300-307.

Ward TR and Mundy WR (1996) Organophosphorus compounds preferentially affect second messenger systems coupled to M2/M4 receptors in rat frontal cortex. Brain Res Bull 39:49-55.

Watkins JC and Evans RH (1981) Excitatory amino acid transmitters. Annu Rev Pharmacol Toxicol 21:165-204.

Whitlock JR, Heynen AJ, Shuler MG, and Bear MF (2006) Learning induces longterm potentiation in the hippocampus. Science 313:1093-1097.

Williamson AM and Sarvey JM (1985) Effects of cholinesterase inhibitors on evoked responses in field CA1 of the rat hippocampus. J Pharmacol Exp Ther 235 448-455.

Wright LK, Liu J, Nallapaneni A, and Pope CN (2010) Behavioral sequelae following acute diisopropylfluorophosphate intoxication in rats: comparative effects of atropine and cannabinomimetics. Neurotoxicol Teratol 32:329-335.

Address correspondence to: John J. Wagner, 501 DW Brooks Drive, Department of Physiology \& Pharmacology, Athens, GA 30602. E-mail: jwagner@uga.edu 